\title{
Adult cardiac stem cells are multipotent and robustly myogenic: c-kit expression is necessary but not sufficient for their identification
}

\author{
Carla Vicinanza ${ }^{1,8}$, Iolanda Aquila ${ }^{1,8}$, Mariangela Scalise ${ }^{1}$, Francesca Cristiano ${ }^{2}$, Fabiola Marino ${ }^{1,3}$, Eleonora Cianflone ${ }^{1}$, \\ Teresa Mancuso ${ }^{1}$, Pina Marotta ${ }^{1}$, Walter Sacco ${ }^{1}$, Fiona C Lewis ${ }^{3}$, Liam Couch $^{4}$, Victoria Shone ${ }^{3}$, Giulia Gritti ${ }^{3}$, Annalaura Torella ${ }^{5}$, \\ Andrew J Smith ${ }^{1,6}$, Cesare MN Terracciano ${ }^{4}$, Domenico Britti ${ }^{7}$, Pierangelo Veltri ${ }^{2}$, Ciro Indolfi ${ }^{1}$, Bernardo Nadal-Ginard ${ }^{\star, 1,9}$, \\ Georgina M Ellison-Hughes ${ }^{\star, 3,9}$ and Daniele Torella ${ }^{*, 1,9}$
}

Multipotent adult resident cardiac stem cells (CSCs) were first identified by the expression of c-kit, the stem cell factor receptor. However, in the adult myocardium c-kit alone cannot distinguish CSCs from other c-kit-expressing (c-kit ${ }^{\text {pos }}$ ) cells. The adult heart indeed contains a heterogeneous mixture of $c-k^{\text {pit }}{ }^{\text {pos }}$ cells, mainly composed of mast and endothelial/progenitor cells. This heterogeneity of cardiac $c$-kit ${ }^{\text {pos }}$ cells has generated confusion and controversy about the existence and role of CSCs in the adult heart. Here, to unravel CSC identity within the heterogeneous $\mathrm{c}$-kit-expressing cardiac cell population, $\mathrm{c}$-kit ${ }^{\mathrm{pos}}$ cardiac cells were separated through CD45-positive or -negative sorting followed by c-kit ${ }^{\text {pos }}$ sorting. The blood/endothelial lineage-committed (Lineage $\left.^{\text {pos }}\right)^{C D} 45^{\text {pos }} c-k_{i t}^{\text {pos }}$ cardiac cells were compared to $\mathrm{CD} 45^{\text {neg }}\left(\right.$ Lineage $^{\text {neg }} /$ Lin $^{\text {neg }}$ ) c-kit ${ }^{\text {pos }}$ cardiac cells for stemness and myogenic properties in vitro and in vivo. The majority $(\sim 90 \%)$ of the resident c-kit ${ }^{\text {pos }}$ cardiac cells are blood/endothelial lineagecommitted $\mathrm{CD} 45^{\mathrm{pos}} \mathrm{CD} 31^{\mathrm{pos}} \mathrm{c}$-kit ${ }^{\mathrm{pos}}$ cells. In contrast, the Lin ${ }^{\text {neg }} \mathrm{CD} 45^{\text {neg }} \mathrm{c}$-kit ${ }^{\text {pos }}$ cardiac cell cohort, which represents $\leqslant 10 \%$ of the total c-kit ${ }^{p o s}$ cells, contain all the cardiac cells with the properties of adult multipotent CSCs. These characteristics are absent from the $c$-kit ${ }^{\text {neg }}$ and the blood/endothelial lineage-committed c-kit ${ }^{\text {pos }}$ cardiac cells. Single Lin $^{\text {neg }} c-k i t^{\text {pos }}$ cell-derived clones, which represent only $1-2 \%$ of total $c$-kit ${ }^{\text {pos }}$ myocardial cells, when stimulated with TGF- $\beta /$ Wnt molecules, acquire full transcriptome and protein expression, sarcomere organisation, spontaneous contraction and electrophysiological properties of differentiated cardiomyocytes (CMs). Genetically tagged cloned progeny of one $\mathrm{Lin}^{\mathrm{neg}} \mathrm{C}$-kit ${ }^{\text {pos }}$ cell when injected into the infarcted myocardium, results in significant regeneration of new CMs, arterioles and capillaries, derived from the injected cells. The CSC's myogenic regenerative capacity is dependent on commitment to the CM lineage through activation of the SMAD2 pathway. Such regeneration was not apparent when blood/endothelial lineage-committed c-kit ${ }^{\text {pos }}$ cardiac cells were injected. Thus, among the cardiac c-kit ${ }^{\text {pos }}$ cell cohort only a very small fraction has the phenotype and the differentiation/regenerative potential characteristics of true multipotent CSCs.

Cell Death and Differentiation (2017) 24, 2101-2116; doi:10.1038/cdd.2017.130; published online 11 August 2017

A variety of endogenous resident cardiac stem/progenitor cells (CSCs) have been isolated from the adult mammalian heart through their expression of different surface markers or alternatively through their ability to form cardiospheres (CS) in vitro. ${ }^{1-8}$ Originally, the adult CSCs were characterised by the expression of the stem cell factor receptor kinase c-kit while being negative for the blood/endothelial cell lineage markers. ${ }^{1}$ These c-kit-positive (c-kit ${ }^{\text {pos }}$ ) CSCs have been shown to be clonogenic, self-renewing and multipotent in vitro and in vivo., ${ }^{1,9-14}$ In addition, transplantation of CSCs into damaged myocardium and their subsequent ablation demonstrated that the CSCs are necessary and sufficient for myocardial regeneration. ${ }^{9}$

c-kit is expressed by a heterogeneous cell population within the heart, ${ }^{10,15-18}$ yet it has often been assumed that the lone identification of c-kit expression in a cardiac cell equates to the identification of a CSC. ${ }^{19-24}$ This broad extrapolation has produced considerable controversy about 'c-kit ${ }^{\text {pos }}$ cardiac

\footnotetext{
${ }^{1}$ Molecular and Cellular Cardiology, Department of Medical and Surgical Sciences, Magna Græcia University, 88100 Catanzaro, Italy; ${ }^{2}$ Bioinformatics Laboratory, Department of Medical and Surgical Sciences, Magna Graecia University, 88100 Catanzaro, Italy; ${ }^{3}$ School of Basic and Medical Biosciences, Faculty of Life Sciences \& Medicine, Kings College London, Guy's campus, London SE1 1UL, UK; ; Laboratory of Cell Electrophysiology, National Heart and Lung Institute, Imperial College, London SW7 2AZ, UK; ${ }^{5}$ TIGEM (Telethon Institute of Genetics and Medicine) and Department of Biochemistry, Biophysics and Molecular Pathology, Second University of Naples, Naples, Italy; ${ }^{6}$ School of Biomedical Sciences, Faculty of Biological Sciences, University of Leeds, Leeds LS2 9JT, UK and ${ }^{7}$ Interdepartmental Veterinary Services Centre, Department of Health Sciences, Magna Græcia University of Catanzaro, 88100 Catanzaro, Italy

${ }^{*}$ Corresponding author: D Torella or B Nadal-Ginard, Molecular and Cellular Cardiology, Department of Medical and Surgical Sciences, Magna Graecia University, Catanzaro, 88100, Italy. Tel: +3909613694185

or GM Ellison-Hughes, School of Basic and Medical Biosciences, Faculty of Life Sciences \& Medicine, Kings College London, Guy's campus, London SE1 1UL. Tel: +44 207 848 6074; E-mail: dtorella@unicz.it or bernardo.nadalginard@gmail.com or georgina.ellison@kcl.ac.uk

${ }^{8}$ These authors equally contributed to this work.

${ }^{9}$ These authors share the senior authorship for this study.

Received 05.4.17; revised 14.6.17; accepted 03.7.17; Edited by R De Maria; published online 11.8.17
} 
a

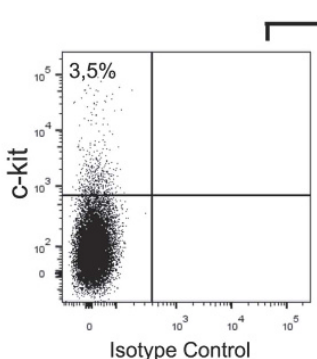

b
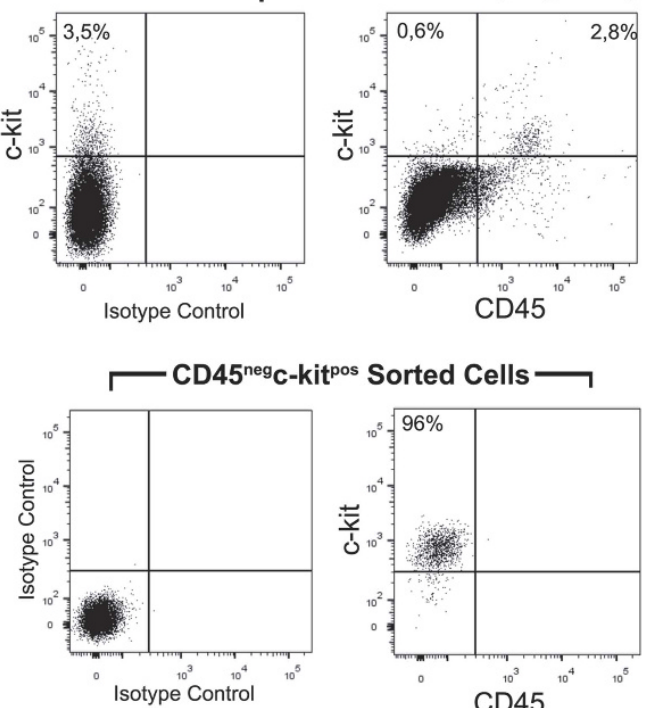

Myocyte-depleted Cardiac Cells $\longrightarrow$
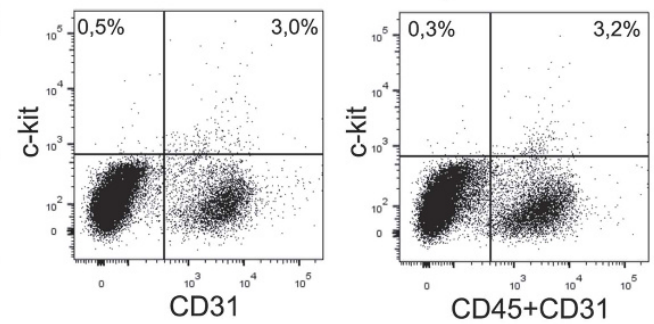

C CD45 $^{\text {neg }}$ C-kit ${ }^{\text {pos }}$ Sorted Cells

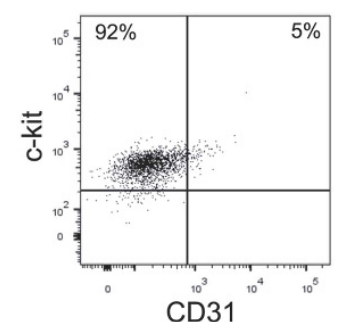

d

Freshly Isolated CD45 ${ }^{\text {neg }}$ C-kit ${ }^{\text {pos }}$ Myocyte-depleted Cardiac Cells
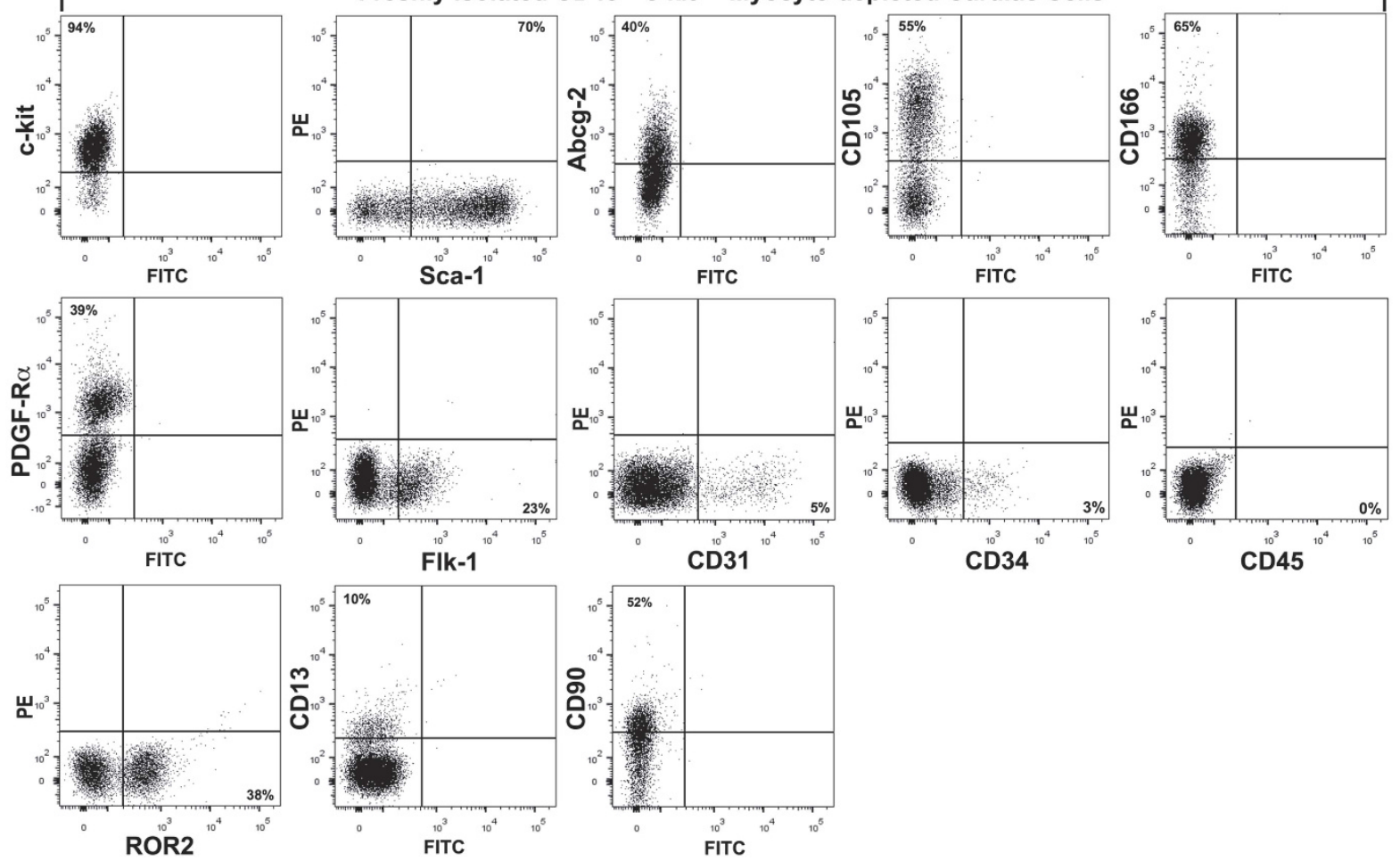

e

Myocyte-depleted Cardiac Cell

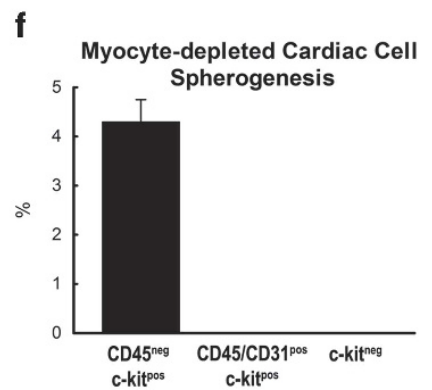

g

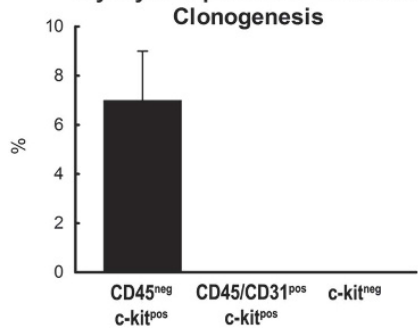

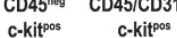

g

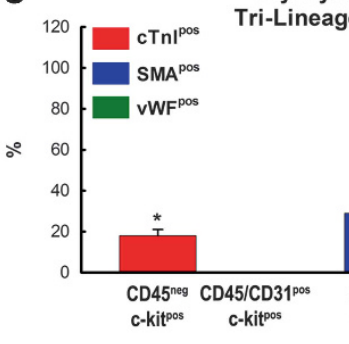

Myocyte-depleted Cardiac Cell

-Lineage Differentiation Potential

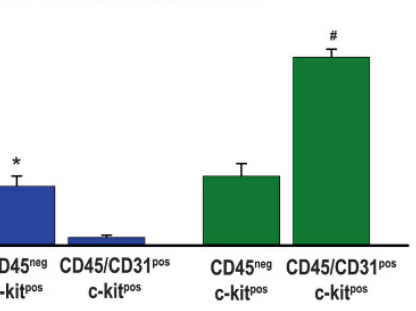


cells' ${ }^{19-26}$ Recently, several groups have used the Cre/lox genetic cell-fate-mapping strategy to track the fate of c-kit ${ }^{\text {pos }}$ cells. $^{22-24}$ This approach marks a myocardial c-kit ${ }^{\text {pos }}$ cell population, which in vivo mainly/exclusively differentiated into endothelial or lymphoid lineage cells but minimally generated new cardiomyocytes (CMs)..$^{22-24}$ Overlooking the heterogeneity of c-kit-expressing cardiac cell cohort, these cell-fatemapping results were interpreted as evidence that c-kit ${ }^{\text {pos }}$ CSCs have a minimal/negligible cardiomyogenic potential. ${ }^{19,22-25}$

Here we show through clonal derivation, the only reliable method to identify a stem cell, ${ }^{27}$ that a cell population comprising $\leqslant 1 \%$ of all cardiac c-kit ${ }^{\text {pos }}$ cells possess clonogenic, self-renewing and cardiac multilineage differentiation potential in vitro and in vivo. Therefore, c-kit expression by itself is not sufficient to identify, isolate and/or track the fate of true CSCs.

\section{Results}

A small fraction of $\mathrm{c}-\mathrm{kit}^{\text {pos }}$ cardiac cells in the adult heart possess tissue-specific stem/progenitor characteristics. c-kit ${ }^{\text {pos }}$ cells were isolated and analysed from adult C57BL/6J mouse or Wistar rat hearts. ${ }^{15}$ Most cardiac c-kit ${ }^{\text {pos }}$ cells in myocyte-depleted cell preparations co-express blood/ endothelial cell lineage commitment markers ( Lin $^{\text {pos }}$ ) such as CD45 and CD31 (Figure 1a). CD45 and CD31 are expressed by $85 \pm 5 \%$ of cardiac c-kit ${ }^{\text {pos }}$ cells (which also includes all the cells expressing CD34) while only $\sim 10 \%$ are negative for blood/endothelial lineage markers $\left(\mathrm{Lin}^{\text {neg}}\right)$ (Figure 1a).

Freshly isolated mouse cardiac cells negatively sorted for CD45 and positively sorted for c-kit are negative for CD45 $(0 \%)$ and positive for c-kit (>95\%; Figure 1b). Because of the overlap in expression of CD45 and CD31 in the CD45 ${ }^{\text {neg }} C$ kit $^{\text {pos }}$ cells, CD45 depletion removes all, or almost all, the CD31 $1^{\text {pos }} /$ CD34 ${ }^{\text {pos }}$ cells from the total $\mathrm{c}$-kit ${ }^{\text {pos }}$ cardiac cells (Figure 1c). CD $45^{\text {neg }} \mathrm{c}-\mathrm{kit}^{\text {pos }}$ cardiac cells are practically

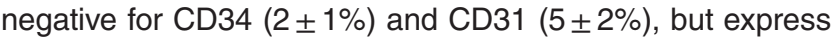
(in different percentages) Sca-1 (60 $\pm 10 \%)$, Abcg2 (45 $\pm 9 \%$ ), CD105 (53 $\pm 8 \%)$, CD166 (58 $\pm 11 \%)$, PDGFR- $a(40 \pm 7 \%)$, Flk-1 (or KDR; $30 \pm 8 \%$ ), ROR2 (38 $\pm 4 \%)$, CD13 (10 $\pm 4 \%$ ) and CD90 (46 $\pm 7 \%$; Figure 1d; Supplementary Figure S2).
Freshly isolated rat $\mathrm{CD} 45^{\text {neg }} \mathrm{C}-\mathrm{kit}^{\text {pos }}$ cardiac cells have a similar profile (Supplementary Figure S1).

CD $45^{\text {neg }} c-$ kit $^{\text {pos }}$ cardiac cells express Tert $(47 \pm 4 \%)$, Bmi-1 ( $51 \pm 4 \%$; Supplementary Figure S3), regulatory genes of stem cell proliferation and self-renewal, ${ }^{28}$ as well as the transcription factors that predict cardiac differentiation

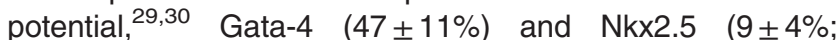
Supplementary Figure S3). Quantitative RT-PCR revealed that freshly isolated mouse $\mathrm{CD} 45^{\text {neg }} \mathrm{C}-\mathrm{kit}^{\text {pos }}$ cardiac cells express all the above markers along with the pluripotency genes Oct-4, Nanog, Klf-4 and Sox-2, and other genes implicated in stem cell renewal and cardiac development (Supplementary Figure S3).

From 1056 single mouse CD45 ${ }^{\text {neg }}$ C-kit ${ }^{\text {pos }}$ cells seeded in 96-well plates in $20 \% \mathrm{O}_{2}$, clones were detected in only 3 wells (Supplementary Figure S3). In contrast, when CD45 ${ }^{\text {neg }}{ }$-kit ${ }^{\text {pos }}$ cardiac cells were allowed to recover after isolation as a bulk culture for one cell passage (P1), we detected $2 \pm 1 \%$ clonal growth. It is most likely that cell cycle activation among 'selfrenewing' cells may explain the clonogenic difference. ${ }^{31}$ This conclusion is supported by the low basal proliferative activity ( $5 \pm 2 \%$ BrdU incorporation; Supplementary Figure S3) of the freshly isolated $C D 45^{\text {neg }} \mathrm{C}$-kit ${ }^{\text {pos }}$ cells, compared to the cells re-plated at P1 (88 $\pm 7 \%$ BrdU incorporation; Supplementary Figure S3). The P1 cells maintained a profile of membrane markers similar to the freshly isolated cells (Supplementary Figure S4). For this reason, we have generally used P1 cells as baseline. As expected, the cloning efficiency of CD $45^{\text {neg }}$ C-kit ${ }^{\text {pos }}$ cardiac cells improves significantly when grown in physiological $\mathrm{O}_{2}$ concentration $\left(3 \% \mathrm{O}_{2}\right)$, reaching $7 \pm 2 \%$ (Figure 1e).

CD45 ${ }^{\text {neg }}$ C-kit ${ }^{\text {pos }}$ cardiac cells grown in suspension at $20 \% \mathrm{O}_{2}$ formed CS at a rate of $2200 \pm 450$ per $10^{5}$ plated cells (Supplementary Figure S3) and these increased to $4300 \pm 1200$ per $10^{5}$ cells in $3 \% \mathrm{O}_{2}$ (Figure $1 \mathrm{f}$ ). $\mathrm{CD} 45^{\text {neg }}{ }_{\mathrm{C}-\mathrm{kit}}{ }^{\text {pos }}$ cardiac cells grown in differentiation media for endothelial (EC), smooth muscle (SMC) and CM lineages, respectively, acquired phenotypic characteristics of these cell types (Figure 1g; Supplementary Figure S3), but at different frequencies (Figure 1g).

In contrast, Lin ${ }^{\text {pos }} \mathrm{c}-\mathrm{kit}^{\text {pos }}$ cardiac cells (i.e., CD45 ${ }^{\text {pos }}$ CD $31^{\text {pos }}{ }^{\text {c-kit }}{ }^{\text {pos }}, \sim 90 \%$ of total myocardial c-kit ${ }^{\text {pos }}$ cells) did not form spheres or show clonal expansion when grown in 20

Figure 1 Phenotype and tissue-specific stem/progenitor potential of freshly isolated myocyte-depleted c-kit ${ }^{\text {pos }}$ cardiac cells. (a) Flow cytometry dot plots (representative of $n=6$ ) show the percentage of total c-kit ${ }^{\text {pos }}$ cells ${ }^{\dagger}, c-k i t^{\text {pos }} / \mathrm{CD} 45^{\text {pos }}$ and $\mathrm{c}-\mathrm{kit}^{\mathrm{pos}} / \mathrm{CD} 31^{\text {pos }}$ within the myocyte-depleted cardiac cells of adult mouse hearts. Right panel shows that the majority of c-kit ${ }^{\text {pos }}$ cardiac cells ( $\left.\sim 90 \%\right)$ are either CD45- or CD31-positive, while only a minority ( 10\%) are CD45- and CD31-negative. (b) Flow cytometry dot plot shows that after sequential CD45-negative and c-kit-positive sorting, sorted cardiac cells are uniformly CD45-negative and homogenously c-kit-positive. (c) Flow cytometry dot plot shows that $\mathrm{CD} 45^{\text {neg }} \mathrm{c}_{\text {-kit }}{ }^{\text {pos }}$ sorted cardiac cells contain a miniscule fraction of CD31-positive cells. (d) Flow cytometry dot plots (representative of $n=5$ ) for membrane $C D$ markers of freshly isolated and MACS-sorted CD45 ${ }^{\text {neg }} \mathrm{C}-\mathrm{kit}^{\mathrm{pos}}$ cardiac cells from normal adult mouse hearts (for each FACS analysis a minimum of six digested hearts were pooled together before MACS sorting). For FACS isotype control antibodies see Supplementary Figure S2. (e-g) Bar graphs show clonogenic capacity (e), and CS formation (f) in myocyte-

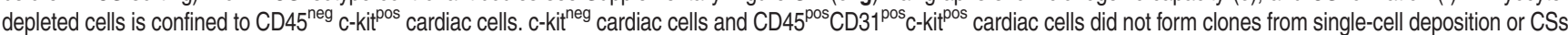
from $10^{5}$ plated cells. Data are mean \pm S.D., $n=10$ (clonogenicity), $n=6$ (CS formation). (g) Bar graphs show that cardiac tri-lineage (CM, $\mathrm{CTnl}$; SMC, SMA ${ }^{\text {pos; }} \mathrm{EC}, \mathrm{vWF}^{\text {pos }}$ ) differentiation capacity in myocyte-depleted cells is confined to $\mathrm{CD} 45^{\text {neg }} c$-kit ${ }^{\text {pos }}$ cardiac cells as evaluated by quantitative immunocytochemistry analysis showing, respectively, that $34 \pm 6 \%$ of them became vWF-positive in basic EC media; $29 \pm 5 \%$ became SMA-positive in basic SMC media; and $18 \pm 3 \%$ became cTnl-positive cells in CM differentiation media. ${ }^{C D} 45^{\text {pos }} C D 31^{\text {pos }} \mathrm{C}-$ kit ${ }^{\text {pos }}$ almost exclusively differentiate into endothelial vWF ${ }^{\text {pos }}$ cells $(92 \pm 4 \%)$ while negligibly became cTnl-positive $(<0.00001 \%)$ and only $5 \pm 1 \%$ acquired SMA expression in the relative specific differentiation media. Data are mean \pm S.D., $n=10{ }^{\dagger}$ The yield of total $c-k i t^{p o s}$ cells after heart dissociation is somewhat variable depending on the age of the animal, the stock of collagenase and duration of the coronary retro-perfusion step $;^{15}$ this variability does not affect, or does so minimally, the final harvest of CSCs 
or $3 \% \mathrm{O}_{2}$ (Figures 1e and $\mathrm{f}$ ), and became vWF-positive in EC differentiation conditions (Figure 1g). Similarly, c-kit ${ }^{\text {neg }}$ cardiac cells neither cloned/formed CSs (Figures $1 \mathrm{e}$ and f). Lin ${ }^{\text {pos }} \mathrm{C}-\mathrm{kit}^{\text {pos }}$ cardiac cells plated in cardiomyogenic medium, negligibly became cTnl-positive (Figure 1g) and in SMC media only a small number acquired smooth muscle actin (SMA) expression (Figure 1g).

Overall, c-kit expression is necessary but not sufficient to identify and enrich for the small population of cells with CSC properties. On its own, c-kit expression in the myocardium mainly identifies the vastly more numerous lineage-committed mast and endothelial cells and their precursors. CD45negative selection followed by c-kit-positive sorting enriches for cardiac cells that exhibit stem/progenitor characteristics. This double selection still yields a progenitor cell population with a heterogeneous phenotype and developmental potential, comprising a mixture of primitive cells and more committed progenitors. Thus, true CSC identity can only be resolved by testing the fate of single cells.

Clonal phenotype of CSCs in vitro. The identification and phenotypic characterisation of the multipotent and cardiomyogenic cohort among the CD45 ${ }^{\text {neg }} \mathrm{c}$-kit ${ }^{\text {pos }}$ cells was performed using single-cell-derived clones from rats for better experimental suitability. ${ }^{15}$ CD $45^{\text {neg }}$ C-kit ${ }^{\text {pos }}$ cells were magnetic-activated cell sorting (MACS)-sorted from myocyte-depleted rat cardiac cells (Figure 2a). At P1 single cells had $3 \pm 1 \%$ clonal efficiency in $20 \% \mathrm{O}_{2}$, which increased to $8 \pm 3 \%$ in $3 \% \mathrm{O}_{2}$.

Four different CD $45^{\text {neg }} \mathrm{C}-\mathrm{kit}^{\text {pos }} \mathrm{CSC}$ clones (chosen for their early appearance and fastest growth rate) expressed c-kit $(94 \pm 5 \%)$, PDGFR- $a$ (88 $\pm 4 \%)$, CD166 (97 $\pm 2 \%)$, SSEA-1 $(75 \pm 6 \%)$, Nestin $(75 \pm 7 \%)$, CD90 $(20 \pm 8 \%)$, ROR2 (5 $\pm 3 \%)$,

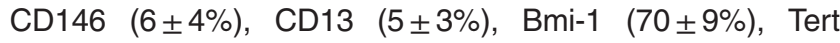
$(88 \pm 13 \%)$, Gata-4 $(83 \pm 11 \%)$ and Nkx2.5 $(70 \pm 8 \%)$, while they were (practically) negative for CD45 (0\%), CD31 ( $\pm 1 \%)$

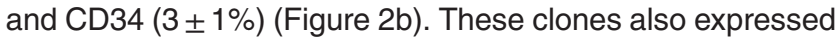
Oct3/4 (85 $\pm 8 \%)$, Nanog ( $80 \pm 6 \%)$, Klf-4 (77 $\pm 8 \%)$ and Sox-2 ( $75 \pm 11 \%$; Supplementary Figure S5). A similar multi-marker expression profile was obtained from typical mouse CSC clones (Supplementary Figure S6). This multiple membrane marker profile includes most, if not all, the markers, which have been used to identify all the reported CSC populations. ${ }^{1-8,15}$ Intriguingly, expression of the mouse-specific CSC marker Sca-1 is correlated with and dependent on the substrate culture conditions. Sca-1 significantly decreased when the clones were grown unattached in Methocult media; Sca-1 expression increased significantly after re-plating these Sca$1^{\text {neg/low }}$ colonies as adherent cells (Figure 2c). Similar attachment-dependence was noticed for CD44, CD105 and CD63 expression (data not shown).

RNA-seq analysis of the global transcriptome of the four rat CSC clones shows enrichment for genes involved in stem cell self-renewal, multipotency, cell cycle, RNA processing, cardiac development and developmental plasticity when searched through gene ontology (GO) terms by DAVID and IPA (Figures 2d and e). The global averaged Pearson's and Spearman's correlation coefficients between pairwise comparisons were very high (Figure 2f) and corresponds to very similar transcriptional programme, which is a strong indication that the four clones are members of a single multipotent CSC type.

CSC clones have a $20 \pm 2 \mathrm{~h}$ doubling time and have been propagated for more than 65 passages and serially sub-cloned with high efficiency every 10 passages (Figure 3a). They have maintained a stable phenotype without signs of growth arrest, senescence or downregulation of stemness and cardiac gene expression (Figure 3b), and a normal karyotype without detectable chromosomal alterations (Supplementary Figure S5). Cloned CSCs generate CSs at high frequency, which give rise to secondary and tertiary CSs (Figure 3c). When placed in laminin-coated plastic dishes with LIF-deprived basic differentiation medium for 14 days the peripheral cells of the sphere expressed proteins specific of the CM, EC and SMC lineages (Figure 3d).

CSC cloned cells plated in Methocult media at serial dilutions to obtain colony-forming units (CFUs), formed colonies with high efficiency even at a dilution of a single cell/ml (Figures $3 e$ and f). In contrast, freshly isolated, noncloned $\mathrm{CD} 45^{\text {neg }} \mathrm{C}-\mathrm{kit}^{\text {pos }}$ cardiac cells, plated at a minimal density of 50 cells $/ \mathrm{ml}$ formed colonies at a frequency of $2 \pm 1 \%$ (Figure 3e). Furthermore, density and cell number were significantly higher in CSC clone-derived colonies than those from freshly isolated, non-cloned CSCs (Figure 3f). Cloned CSCs had a higher re-cloning efficiency, CS formation and multipotent differentiation potential than non-cloned, bulk culture P1 cells (Figures $3 g-i)$.

These results show that all the cells with CSC characteristics are confined to the CD $45^{\text {neg }} \mathrm{C}-\mathrm{kit}^{\text {pos }}$ cell population and none of the data supports the notion that the adult mammalian myocardium harbours a population of c-kit ${ }^{\text {neg }}$ CSCs. Only $\sim 10 \%$ of $\mathrm{CD} 45^{\text {neg }} \mathrm{c}$-kit ${ }^{\text {pos }}$ cardiac cells (which in turn are $\sim 10 \%$ of the total cardiac c-kit ${ }^{\text {pos }}$ population) are clonogenic and multipotent. Therefore, the cells with a demonstrable multipotent CSC phenotype represent only $1-2 \%$ of the total myocardial c-kit ${ }^{\text {pos }}$ cell population. Given these data, it is confounding to continue using the redundant name 'c-kit"pos CSCs' while 'CSCs' is sufficient.

Classic cardiac morphogens instruct CSC's cardiomyogenic commitment. In the embryonic cardiomyogenic specification process, ${ }^{29,30}$ 'cell-autonomous' decisions operate in combination with 'cell-non-autonomous' events, which depend on extracellular instructive molecules known as morphogens or cardiopoietic growth factors (cGFs). ${ }^{32,33} \mathrm{Wnt} / \beta$-catenin and TGF- $\beta$ /SMAD signalling pathways have well-defined and distinct functions in mammalian cardiogenesis. ${ }^{34-38}$ Through gain- and loss-of-function experiments we investigated their involvement in growth promotion and cardiomyogenic specification of the rat CSCs.

CSCs express the cell-surface receptor of $\mathrm{Wnt} / \beta$-catenin canonical pathway, Frizzled, as well as its co-receptor, lowdensity lipoprotein receptor-related protein 6 (Supplementary Figure S7). Wnt-3a, Wnt-3a-conditioned medium and bromoindirubin-3'-oxime (BIO) stimulated CSC expansion and clonogenicity, while canonical Wnt inhibition decreased CSC proliferation and clonogenicity (Figures $4 a$ and b). These positive and negative modulators of $\mathrm{Wnt} / \beta$-catenin acted through, respectively, stabilising or degrading $\beta$-catenin and its LEF/TCF-dependent transcriptional activity (Figure 4c). 
a
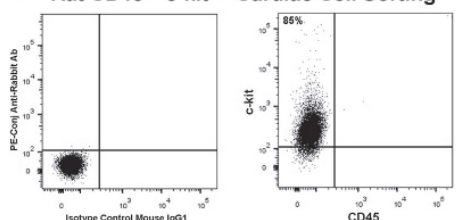

C

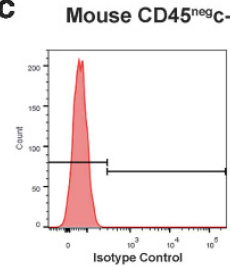
MethoCult
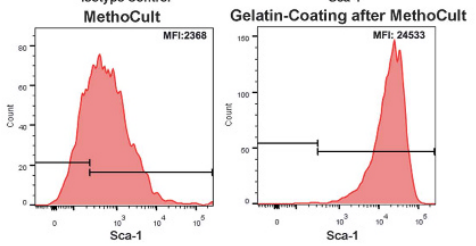

b
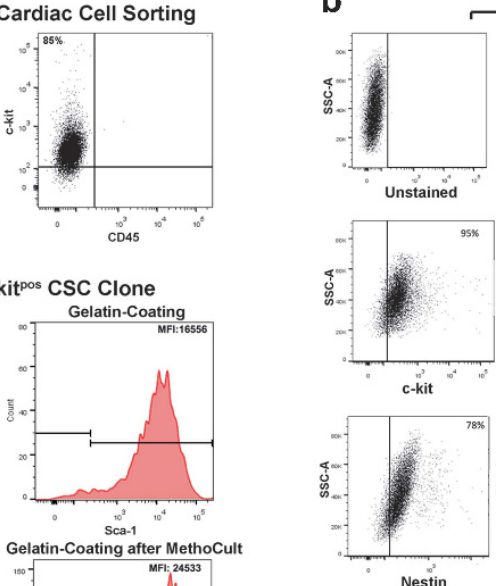

Nestin

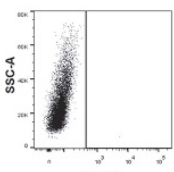

CD45
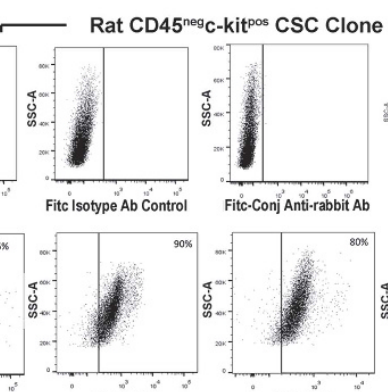

PDGF-R $\alpha$

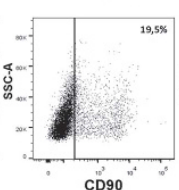

SSEA-1
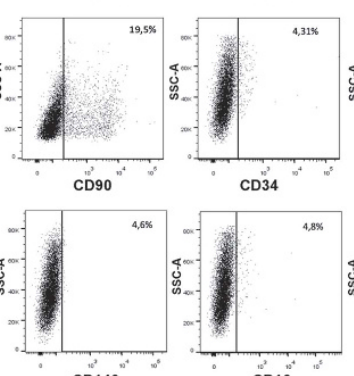

CD146

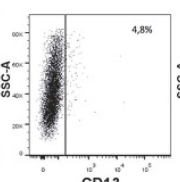

$\mathrm{CD} 13$

e

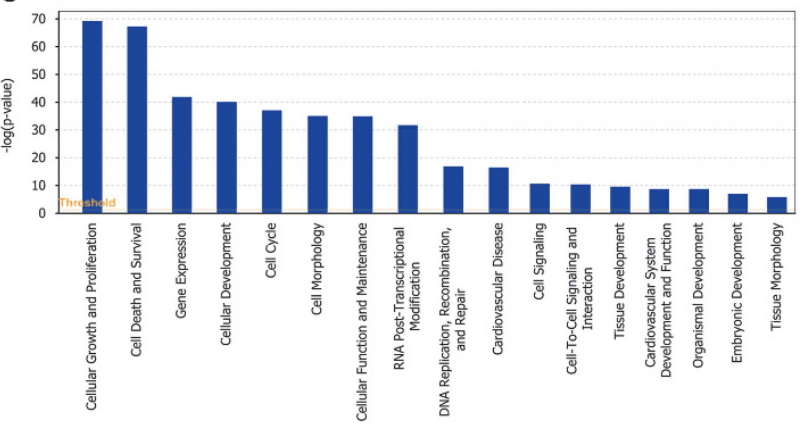

\section{d $\quad$ csc Clones}

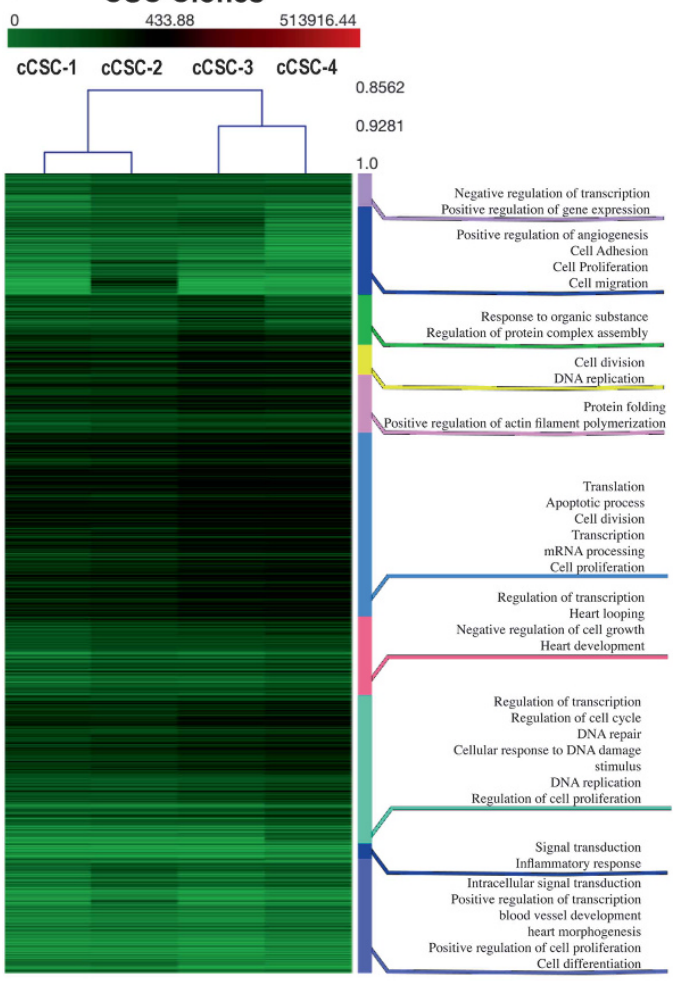

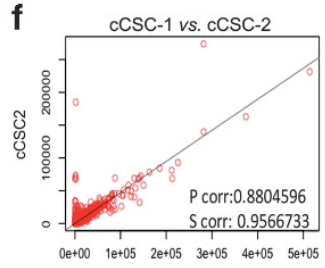

c.sc1

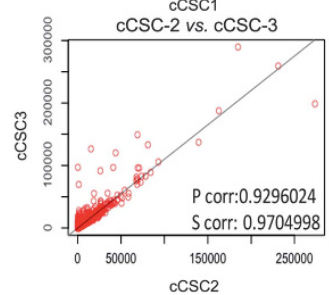

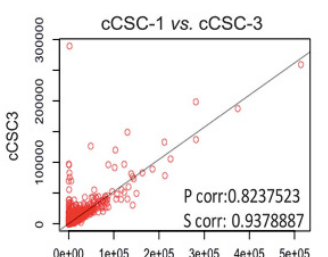

c csc1

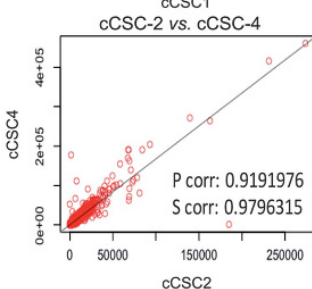

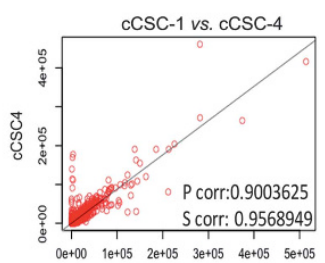

$\operatorname{ccsc} 1$

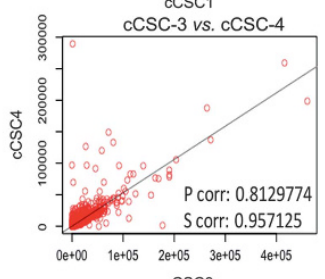

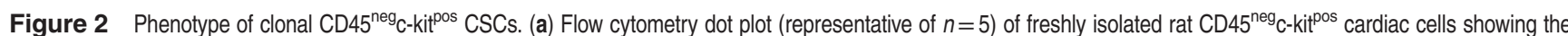
enrichment of this cell population after sequential negative - CD45 - and positive - c-kit - cell sorting from the total myocyte-depleted cardiac cells. (b) Flow cytometry dot plots and confocal images from cytospin preparations (representative of $n=6$ ) showing the $C D$ membrane phenotype and nuclear markers of a typical clone of rat $C D 45^{\text {neg }} C-k$ kit $^{\text {pos }}$ CSCs. (c) Flow cytometry histograms (representative of $n=3$ ) show that levels of Sca- 1 expression in CD $45^{\text {neg }} c$-kit ${ }^{\text {pos }}$ clonal CSCs is dependent on cell culture. When grown as adherent cells on gelatin-coated dishes $\mathrm{CD} 45^{\text {neg }} \mathrm{c}-\mathrm{kit}{ }^{\text {pos }}$ clonal CSCs express high levels of Sca-1. When transferred into methylcellulose (MethoCult medium) to avoid adherent growth, the level of Sca-1 is significantly reduced. When transferred back onto gelatin-coated dishes Sca-1 expression returns to the original levels. (d) Heat map of the most highly expressed genes ( $>10 \mathrm{mRNA}$ copies) in 4 different rat $\mathrm{CD} 45^{\mathrm{neg}} \mathrm{C}$-kit ${ }^{\text {pos }} \mathrm{CSC}$ clones. The enriched GO terms organised in 10 resulting clusters as analysed by DAVID are shown. (e) Functional categorisation by Ingenuity Pathway Analysis (IPA) of the top expressed genes by RNA-seq of $4 \mathrm{CD}^{\mathrm{n}} 5^{\text {neg }} \mathrm{C}-\mathrm{kit}^{\mathrm{pos}} \mathrm{CSC}$ clones. Histogram represents the most significant canonical pathways generated using IPA software. Ratio was calculated by dividing the number of genes from our data set that map to each single pathway by the total number of genes included into the canonical pathway. (f) Comparisons of global gene expression profiles of 4 different rat $\mathrm{CD}^{\text {neg }} \mathrm{C}-\mathrm{kit}^{\mathrm{pos}} \mathrm{CSC}$ clones. P, Pearson's correlation coefficient; S, Spearman's rank correlation coefficient 
When CSCs were induced to differentiate by LIF withdrawal, Wnt-3a, Wnt-3a-conditioned medium and BIO significantly inhibited differentiation with a concomitantly reduced expression of cardiomyogenic genes (Figure 4d; Supplementary Figure S7), and reduced number of CSCs differentiating into myocyte-committed cells (cTnl ${ }^{\text {pos; }}$ Figure 4e). In contrast, Dickkopf-1 (Dkk-1) increased CSC myocyte specification (Figures $4 d-f$ ), even though its effect was not sufficient to produce a fully differentiated beating phenotype.

CSCs express the cell-surface receptor for TGF- $\beta / S M A D$ signalling, TGF- $\beta$-R1 (Supplementary Figure S7). Supplementation with Activin-A specifically induced SMAD2 phosphorylation in the CSCs (Figure 4g). Conversely, Smad2 ${ }^{\text {shRNA }}$ reduced the corresponding mRNA and protein levels (Figure $4 \mathrm{~g}$ ). Neither BMP-2, BMP-4, TGF- $\beta 1$ or Activin-A supplementation nor Smad2 knockdown affected CSC expansion or clonogenicity (Figures $4 \mathrm{~h}$ and i). However, in $\mathrm{CM}$ differentiation medium, BMP-2, BMP-4, TGF- $\beta 1$ and Activin-A, each significantly increased the expression of myogenic lineage markers and the number of cTnl ${ }^{\text {pos }}$ myocyte-committed cells (Figures $4 \mathrm{j}-1$ ). Concordantly, Smad2 ${ }^{\text {shRNA }}$ reduced CSC myocyte specification and completely blocked the Activin-A-dependent positive myogenic effect (Figures 4j and I).

These data show that CSCs respond to known cardiac morphogens as would be expected from true cardiac-specific stem/progenitor cells. Inhibition of the Wnt canonical pathway and TGF- $\beta$ family activation, each independently promotes cardiomyogenic commitment. Nevertheless, individual modulation of each of these cGFs is insufficient to generate fully differentiated contracting CMs.

\section{A stage-specific TGF- $\beta /$ Wnt family inhibitor cocktail promotes CSC differentiation into spontaneously con-} tractile myocytes. We tested whether the $\mathrm{cGFs}^{32,33,38}$ and signalling pathways identified above, when given in a stage-/ sequence-specific manner with or without supplementation with additional factors, stimulated the production of spontaneously contractile CMs from rat cloned CSCs in vitro.

On the basis of the CSC-CS multipotency assay in vitro (Figure 3d), we developed a CS-beating assay similar to those used to assess CM differentiation in embryoid bodies ${ }^{15,38}$ (Supplementary Figure S8). Undifferentiated, clonal CSCderived CSs expressed c-kit, Oct-4, Sox-2, KIf-4, Nanog and Wnt-3a (Supplementary Figure S8). Clonal CSCs were pretreated with $100 \mathrm{nM}$ oxytocin for $72 \mathrm{~h}$, left to form CSs for 3-4 days (Supplementary Figure S8) and subsequently plated on laminin-coated dishes in CM differentiation media deprived of LIF. Supplementation with different concentrations of BMP-4 and Activin-A for 4 days increased to $\sim 40 \%$ the fraction of $\mathrm{cTnl}^{\text {pos }}$ myocyte-committed cells (Figure $5 \mathrm{a}$ ). Adding Dkk-1 from day 5 onwards (Figure $5 a$ ) increased to $\sim 60 \%$ the cTnl $^{\text {pos }}$ cells (Figure $5 \mathrm{a}$ ). Removing BMP-4 and Activin-A at day 5 further increased the number of $c \mathrm{TnI}^{\text {pos }}$ cells to $\sim 70 \%$ (Figures $5 a$ and $b$ ).

qRT-PCR analysis of the main cardiac transcription factors and myocyte contractile genes showed that Gata-4, Nkx2.5, Mef2C and Hand2 are induced in the early time points while contractile genes - Tnnt2, Myl2, Actc1, Myh7, PIn and Atp2a reached their peak of expression at later stages of differentiation (Figure 5c; Supplementary Figure S8). Starting at day 8,
CSC-derived CSs showed robust synchronised beating (Supplementary Movies 1 and 2). When beating spheres at day 21 were dissociated to obtain single beating cells (Supplementary Movie 3), the differentiated CMs had well-organised sarcomeres with clear cross-striations and connexin 43 gap junctions (Figure 5d; Supplementary Figure S8). These data were confirmed by western blots of protein extracts (Supplementary Figure S8).

Spontaneously contractile CSC-derived CMs (hereafter iCMs) analysed for standard electrophysiological properties exhibited robust calcium transients (Figure 5e; Supplementary Figure S8), and when stimulated at $1 \mathrm{~Hz}$ in beating clusters and up to $2 \mathrm{~Hz}$ in monolayer (Supplementary Movie 4), had typical action potentials (Figure 5f). Upon application of $40 \mu \mathrm{M}$ caffeine, a calcium transient (Figure $5 \mathrm{~g}$ ) significantly larger than control transients (Figure $5 \mathrm{~h}$ ) was observed. This behaviour is indicative of a functional sarcoplasmic reticulum in the iCMs. ${ }^{39}$ Mechanisms of calcium transient decay derived using established methods ${ }^{40}$ showed that SERCA and the sodium calcium exchanger (NCX) contributed approximately equally to the $\mathrm{Ca}^{2+}$ re-sequestering into the SR (Figure 5i). These data suggest that both are functionally relevant on a beat-to-beat basis, similarly to CMs derived from pluripotent stem cells ${ }^{41}$ and neonatal CMs (neoCMs). ${ }^{42}$ Application of isoprenaline $(1 \mu \mathrm{M})$ increased the spontaneous beating rate, whereas carbachol $(10 \mu \mathrm{M})$, almost abolished automatic beating (Figure 5j), indicating, respectively, the presence of robust stimulatory $\beta$-adrenergic and inhibitory muscarinic acetylcholinergic signalling pathways. Finally, CSs generated from Smad2 ${ }^{\text {shRNA }}$ CSCs (Supplementary Figure S8) were significantly impaired in CM commitment (Figure 5a).

These results provide indisputable evidence that CSCs are cardiomyogenic and respond to and depend on known cardiac development morphogens to generate contracting cardiac muscle cells.

CSC-derived CMs show the typical gene expression profile of postnatal CMs. To determine whether the iCMs acquire a mature gene expression profile and undergo the typical transcriptional switch, which accompanies permanent cell cycle exit during $\mathrm{CM}$ terminal differentiation, ${ }^{43-45}$ we compared RNA-seq data from CSCs, iCMs, neoCMs and adult CMs (aCMs; Figures 6a-e; Supplementary Table S1a-e).

Comparison of iCMs with CSCs revealed transcription of 11530 genes (Figure 6a) with 1737 genes downregulated and 3709 upregulated (both with a fold change (FC) of 2.5) in the iCMs (Figure 6a; Supplementary Table S1a). The downregulated genes are mainly involved in cell division, DNA replication initiation, DNA repair, cellular response to DNA damage stimulus, stem cell differentiation, organ regeneration and cell proliferation (Figure 6b; Supplementary Table S1b). Conversely, upregulated genes are involved in CM development, sarcomere organisation, regulation of myocardial contraction force, heart development, regulation of heart rate, and calcium and potassium ion transport (Figure 6b; Supplementary Table S1b). Genes critical for sarcomere assembly, which are highly expressed in the adult heart, showed notably increased expression in the CSC-derived iCMs (Figure 6e; Supplementary Table S1e). In addition, genes coding for major inward and outward ion channels, 
a

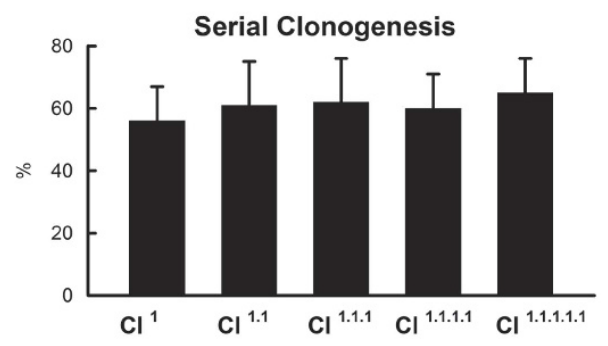

b

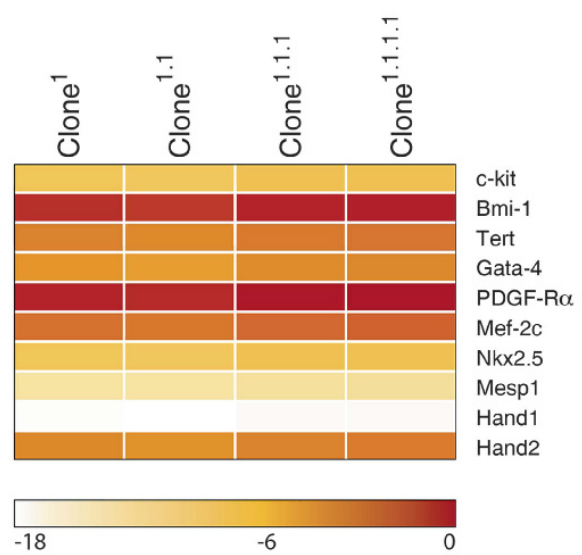

e $70 \quad$ Colony Forming Unit Assay

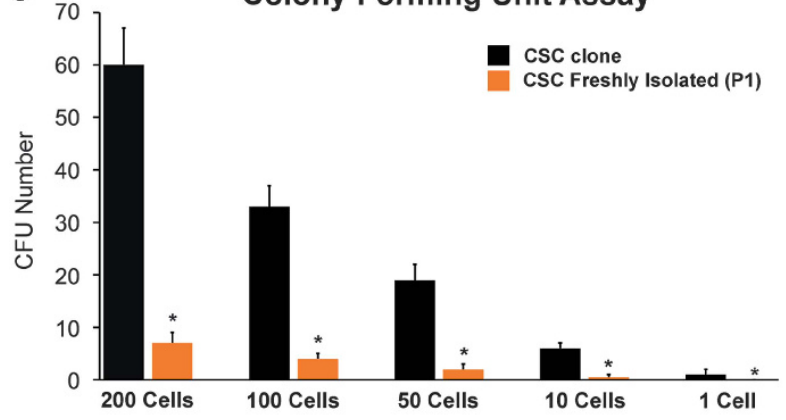

g

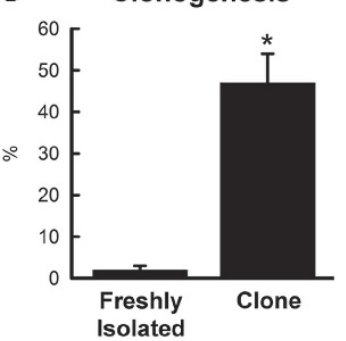

h

d
Cardiospheres from CSC clone
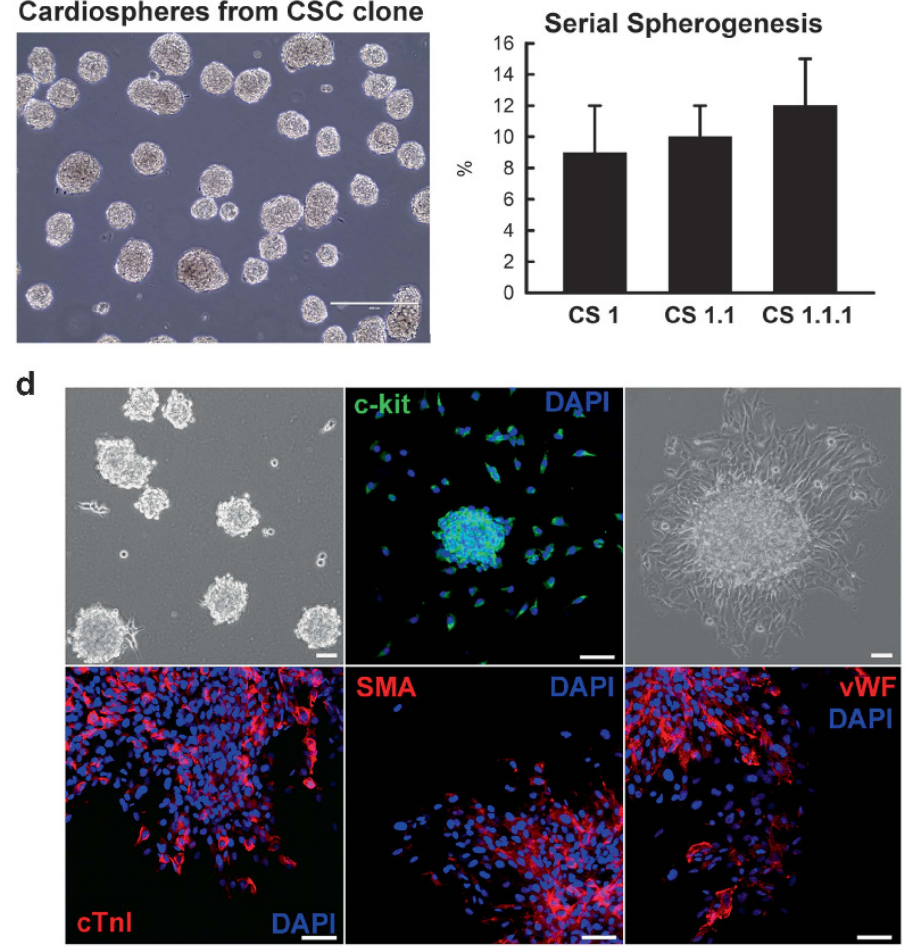

f CSC Freshly Isolated (P1)

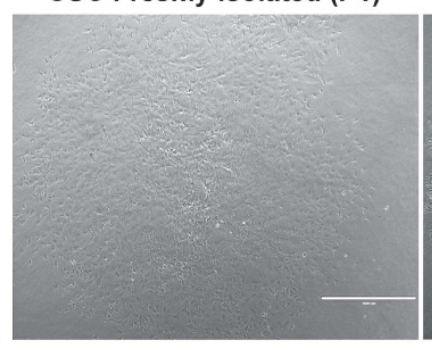

CSC clone

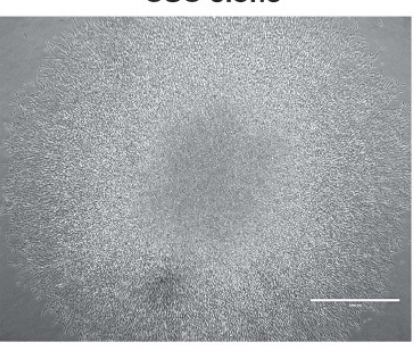

SMC Differentiation
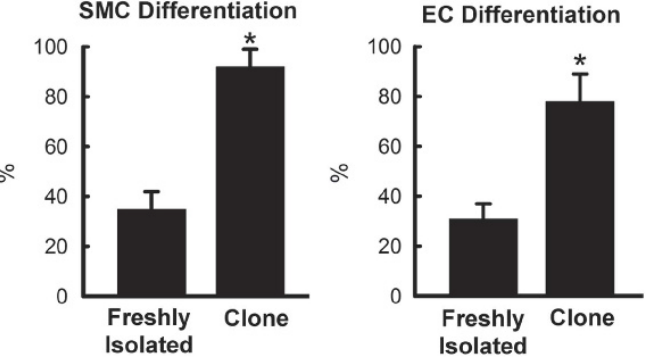

Figure 3 Clonogenicity and differentiation potential of clonal $C D 45^{\text {neg }} \mathrm{C}-k_{i t}{ }^{\text {pos }} \mathrm{CSC}$. (a) Sub-cloning efficiency of a rat c-kit ${ }^{\text {pos }} \mathrm{CSC}$ clone (Cl) at every tenth passage. Data are mean \pm S.D., $n=6$. (b) Serial sub-clones of c-kitpos CSCs, generated at P50 of the respective parental clone, maintained similar expression of multipotent and cardiac transcription factor genes. Colour scale indicates change in $\mathrm{Ct}$ (threshold cycle) relative to the normalised GAPDH control. Higher delta $\mathrm{Ct}$ values correspond to lower relative gene expression, with every $\mathrm{Ct}$ decrease of 3.3 representing a twofold increase in relative expression. (c) Serial spherogenesis efficiency of a clone of c-kit ${ }^{\text {pos }}$ eCSCs (1, primary; 1.1, secondary; 1.1.1, tertiary CSs). Representative image of tertiary CSs are shown in the left panel, bar $=50 \mu \mathrm{m}$. (d) CSs generated from clonal c-kit ${ }^{\text {pos }}$ (green) CSCs plated in basal differentiation media spontaneously commit to the CM (cTnl, red), smooth muscle (SMA, red) and endothelial (vWF, red) cell lineages. Nuclei are stained in blue by DAPI. Bar $=50 \mu \mathrm{m}$. (e) CFU formation of cloned versus freshly isolated (at passage 1, P1) c-kit ${ }^{\text {pos }}$ CSCs plated at different numbers in 1.2 ml of MethoCult medium; ${ }^{*} P<0.05$ versus cloned c-kit ${ }^{\text {pos }}$ CSCs. Data are mean \pm S.D., $n=6$. (f) Representative light microscopy images of a CFU from freshly isolated (P1) c-kitpos CSCs (left panel) and cloned c-kit ${ }^{\text {pos }}$ CSCs (right panel), bar $=50 \mu \mathrm{m}$. (g and $\mathbf{h})$ Clonal-derived c-kit ${ }^{00 s}$ CSCs show greater clonogenic (g) and CS formation (h) potential, when compared to freshly isolated (P1) c-kit ${ }^{\text {pos }}$ CSCs. ${ }^{*} P<0.05$ versus freshly isolated P1. Data are mean \pm S.D., $n=6$. (i) Clonal-derived c-kittos $\mathrm{CSC}$ s show greater differentiation potential into CMs (number of cTnl-positive cells), SMCs (number of SMA-positive cells) and ECs (number of vWF-positive cells), when compared to freshly isolated c-kit ${ }^{\text {pos }}$ CSCs. ${ }^{*} P<0.05$ versus freshly isolated P1. Data are mean \pm S.D., $n=6$ 
calcium-binding proteins, ion receptors, ion exchangers, calcium ATPases and calcium-/calmodulin-dependent protein kinases were upregulated, while cell cycle regulators and cytokinesis were consistently downregulated in the iCMs (Figure 6e; Supplementary Table S1e).

Comparison of iCMs with freshly isolated aCMs identified 8365 genes (out of 13285 detected sequence reads/counts) expressed in both types, with 2385 genes upregulated and 2535 genes downregulated in iCMs (Figure 6a; Supplementary Table S1a). Most of the genes with higher expression in aCMs are involved with sarcomere organisation, contraction through regulation of potassium and calcium ion transport, release of sequestered $\mathrm{Ca}^{2+}$ and regulation of heart rate (Figures $6 \mathrm{c}$ and e; Supplementary Table S1c and e). Contrariwise, almost all of the genes with higher expression in iCMs are involved in cell division, DNA replication, regulation of cell cycle and cell proliferation, as well as DNA recombination and repair (Figures $6 \mathrm{c}$ and e; Supplementary Table S1c and e). Thus, iCMs have not reached complete maturation compared to aCMs.

As expected from the above, transcriptome comparison of iCMs with neoCMs showed the highest similarity. Out of 12507 transcribed genes, 11262 were equally expressed in both cell types (Figure 6) while 703 mRNAs were upregulated
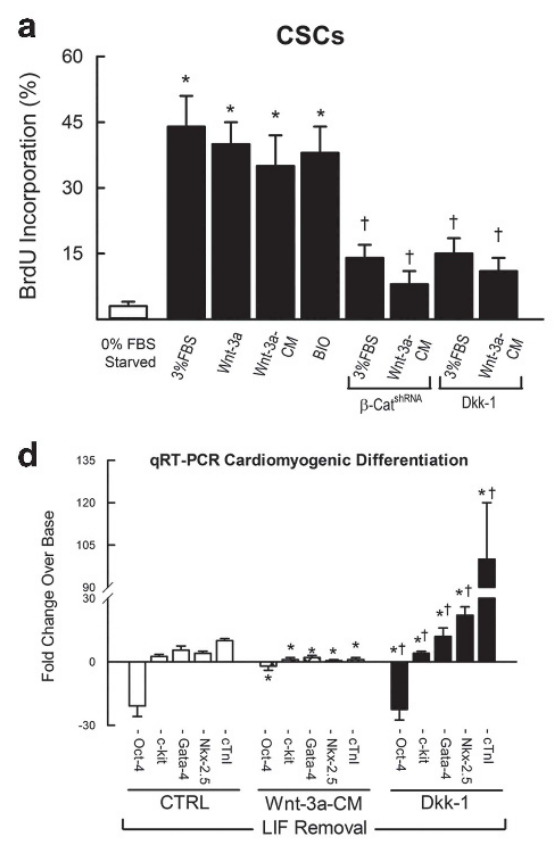

g

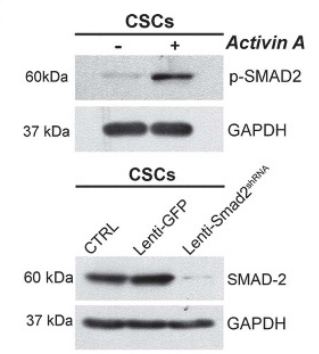

h
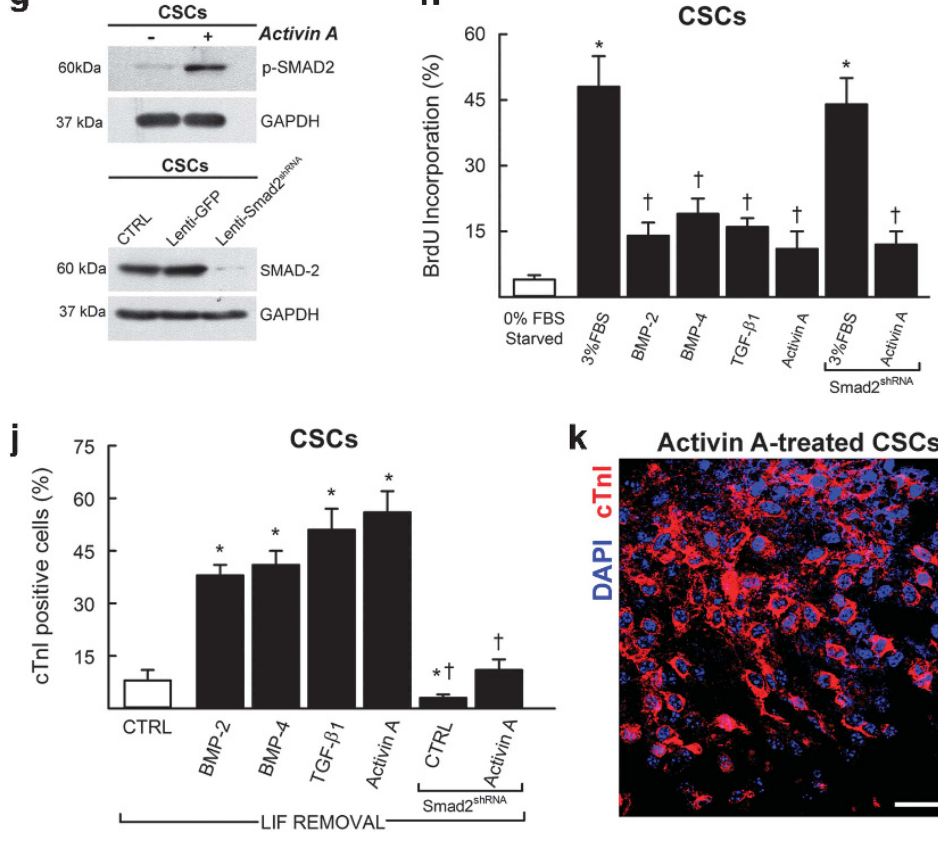

k Activin A-treated CSCs

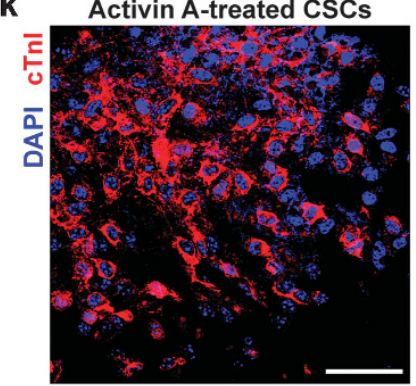

b

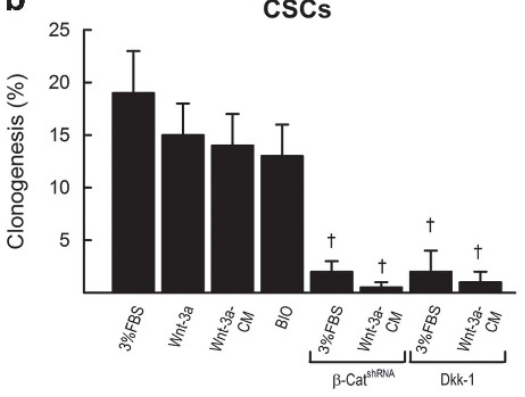

e

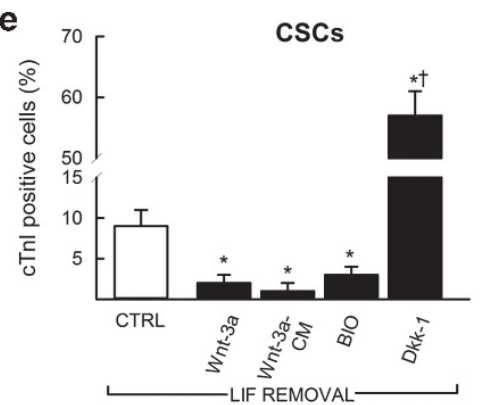

c

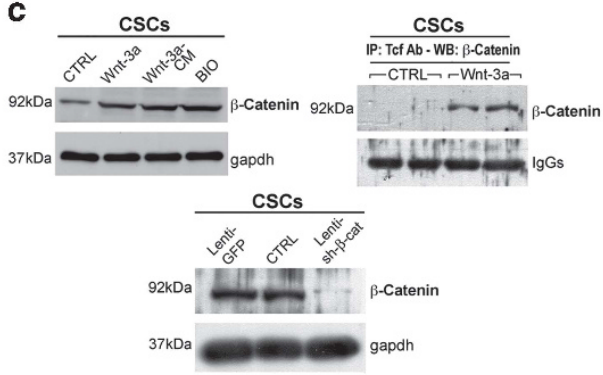

f
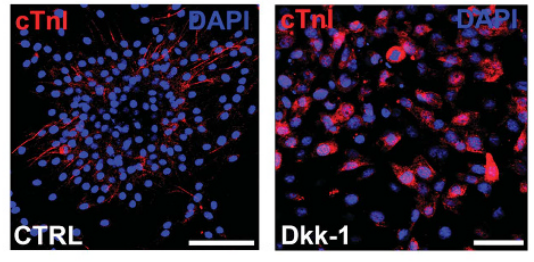

i
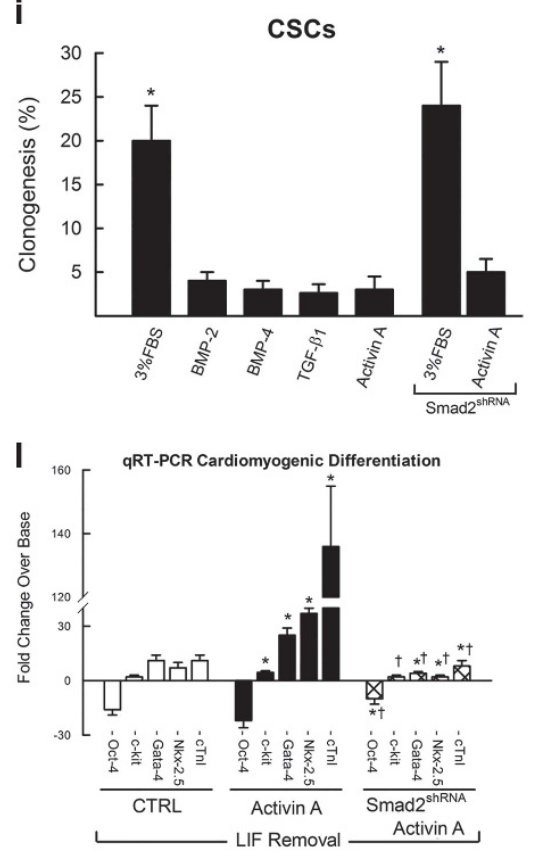
and 542 downregulated in the iCMs (Figure 6a; Supplementary Table S1a). These upregulated genes are mostly involved with cell metabolism (fatty acid biosynthetic and ATP metabolic process) and cell adhesion (negative regulation of cell-matric adhesion; Figure 6d; Supplementary Table 1d) while the downregulated genes are related to cell proliferation and immunity (Figure 6d; Supplementary Table S1d). More importantly, when RNA-seq data for selected cardiac muscle and cell cycle genes for each of the four cell types were clustered, the iCMs' gene expression profile is practically indistinguishable from that of neoCMs (Figure 6e; Supplementary Table S1e).

Overall, CSCs, when properly stimulated in vitro, robustly commit to and differentiate into well-organised and functional CMs.

Clonogenic CSCs, but not the total c-kit ${ }^{\text {pos }}$ cardiac cells, are multipotent in vivo and their progeny is necessary for effective histological and functional myocardial regeneration. In apparent discrepancy with these and previous ${ }^{1,9}$ results, recent publications have reported that the $\mathrm{c}-\mathrm{kit}^{\text {pos }}$ cardiac cells have minimal/absent cardiomyogenic potential. ${ }^{22-24,46}$ However, these reports did not distinguish among different types of $\mathrm{c}^{-\mathrm{kit}^{\mathrm{pos}}}{ }^{\mathrm{c}}$ cardiac cells and assumed that all c-kit ${ }^{\text {pos }}$ cells were putative CSCs. Thus, we tested the regenerative potential of the total cardiac c-kit ${ }^{\text {pos }}$ cell population (constituted by $\sim 99 \%$ of non-CSCs) as compared to true CSCs described here. To genetically mark the total freshly isolated c-kit ${ }^{\text {pos }}$ cardiac cells from adult Wistar rats, they were transduced with a Lenti-GFP construct (Supplementary Figure S9). After experimental acute myocardial infarction (AMI) in syngeneic rats, $2 \times 10^{5}$ GFP ${ }^{\text {pos }} \mathrm{C}-$ kit $^{\text {pos }}$ cells were injected intramyocardial at five sites in the MI border zone. An identical number of GFP-expressing clonogenic CD45 ${ }^{\text {neg }} \mathrm{C}$-kit ${ }^{\text {pos }}$ CSCs (CSC ${ }^{\text {GFP }}$ ) were injected into an additional set of rats. ${ }^{1,9}$ As placebo control, the same number of animals were injected with just PBS.

At 28 days post AMI, CSC ${ }^{\text {GFP }}$ cells were detected in all recipient infarcted hearts (Figure $7 \mathrm{a}$ ), with a significantly higher engraftment rate in the border/infarct zone, compared to the distal myocardium (Figure $7 \mathrm{~b}$ ). The CSC $^{\text {GFP }}$ cells produced a robust myocardial regeneration with formation of new GFP ${ }^{\text {pos }}$ CMs, arterioles and capillaries (Figures 7a and b). As expected for recently born myocytes, most, if not all, new GFP ${ }^{\text {pos }}$ myocytes were mononucleated and of smaller size than the GFP ${ }^{\text {neg }}$ pre-existing, binucleated CMs (Supplementary Figure S9). The CSC ${ }^{\text {GFP }}$ significantly reduced myocyte apoptosis and hypertrophy, significantly decreased scar size and LV dilation while they improved fractional shortening and ejection fraction, compared to salinetreated controls, which were all in heart failure (Figures 7c and d; Supplementary Figure S10; Supplementary Table S2).

The hearts injected with total GFP ${ }^{\text {pos }}{ }^{\mathrm{c}-\mathrm{kit}^{\mathrm{pos}}}$ cardiac cells showed only rare and scattered GFP ${ }^{\text {pos }}$ cell engraftment, which was mostly limited to the infarct/border zone (Figures $7 \mathrm{a}$ and b). A minuscule number of GFP ${ }^{\text {pos }}$ myocytes ( $0.00001 \%$ of total myocardial cell nuclei) was detected and most GFPpos cells $(\sim 90 \%)$ co-stained for vWF, confirming their endothelial lineage and/or phenotype (Figures $7 a$ and b). Most significantly, 28 days after AMI, the total c-kit ${ }^{\text {pos }}$ cardiac cells had not shown any protective effect on cardiac dimensions or function (Figures 7c and d; Supplementary Table S2). Without exception, each of these animals developed overt heart failure (Figures 7c and d).

Finally, SMAD2 knocked-down CSCs (CSC ${ }^{\text {GFP-Smad2shRNA }}$ ) showed similar engraftment in the border/infarct zone to

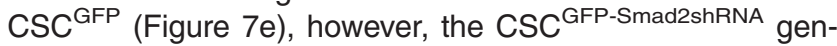
erated $\sim 10$-fold less new myocytes (Figure $7 f$ ), which were significantly smaller than the GFP ${ }^{\text {pos }}$ myocytes generated by the CSC $^{\text {GFP }}$ (Figure $7 \mathrm{~g}$ ). The number of GFP ${ }^{\text {pos }}$ capillaries generated by the CSC GFP and CSC ${ }^{\text {GFP-Smad2shRNA }}$ was similar yet the CSC GFP-Smad2shRNA were significantly less effective in ameliorating cardiac function than the CSC ${ }^{\text {GFP }}$. Nevertheless, the cardiac performance of the CSC ${ }^{\text {GFP-Smad2shRNA }}$-treated animals was slightly better than that of the saline-injected animals at 28 days post AMI (Figure $7 \mathrm{~h}$ ).

Taken together, the results presented here clearly demonstrate that only true clonogenic and multipotent CSCs $(\sim 1-2 \%$

Figure 4 Canonical Wnt and TGF- $\beta 1 /$ SMAD2 pathways govern c-kit ${ }^{\text {pos }}$ CSC fate. (a-f) To promote the $\mathrm{Wnt} / \beta$-catenin pathway we used either soluble Wnt-3a (200 ng/ml), Wnt-3a-conditioned medium from a Wnt-3a-secreting cell line or BIO (2.5 $\mu \mathrm{M}$; a specific inhibitor of GSK-3 that stabilises $\beta$-catenin). To disrupt the Wnt $/ \beta$-catenin pathway, clonal CSCs were treated either with Dkk-1 $(150 \mathrm{ng} / \mathrm{ml})$, an inhibitor of canonical Wnts, or transfected with a lentiviral vector carrying a specific shRNA for $\beta$-catenin $\left(\beta\right.$-cat $\left.{ }^{\text {shRNA }}\right)$. (a and b) Effect of canonical Wnt pathway activation on c-kitpos CSC proliferation (a) and clonogenicity (b). ${ }^{*} P<0.05$ versus $0 \%$ FBS serum starvation (for $48 \mathrm{~h}$ ); ${ }^{\dagger} P<0.05$ versus relative treatment. Data are mean \pm S.D., $n=6$. (c) Western blot analysis shows that the three different treatments to activate Wnt canonical pathway similarly increase $\beta$-catenin levels when compared to untreated (control, CTRL) CSCs. On the right, immunoprecipitation (IP) and western blot analysis shows increased $\beta$-catenin-Tcf nuclear binding in soluble Wnt3a treated versus untreated c-kitpos CSCs. Finally, western blot on the bottom shows efficient downregulation of $\beta$-catenin in c-kit ${ }^{\text {pos }}$ CSCs using a lentiviral shRNA construct. (d) qRT-PCR analysis shows the FC (over c-kit ${ }^{\text {pos }}$ CSCs in base differentiation medium) of Oct-4, c-kit, Gata-4, Nkx2.5 and cTnl mRNA transcripts following 14 days in LIF-deprived differentiation medium in the absence (CTRL) or presence of Wnt3a or Dkk-1. ${ }^{*} P<0.05$ versus CTRL. ${ }^{\dagger} P<0.05$ versus Wnt-3a-CM. Data are mean \pm S.D., $n=3$. (e) Canonical Wnt pathway induction or inhibition by Wnt3a, BIO or Dkk-1 inhibits or increases c-kit ${ }^{\text {pos }} \mathrm{CSC}$ commitment to the CM lineage, respectively. ${ }^{*} P<0.05$ versus $\mathrm{CTRL}$; ${ }^{\dagger} P<0.05$ versus relative treatment. (f) Representative confocal images show CM (red, cTnl) committed cells in CTRL- and Dkk-1-treated c-kit ${ }^{\text {pos }}$ CSCs. DAPI stain nuclei in blue. Bar $=50 \mu \mathrm{m}$. (g-l) To evaluate the role of TGF- $\beta /$ SMAD signalling on CSC activation, BMP-2 (10 ng/ml), BMP-4 (10 ng/ml), TGF- $\beta 1$ ( $5 \mathrm{ng} / \mathrm{ml})$ and Activin-A (10 ng/ml) were

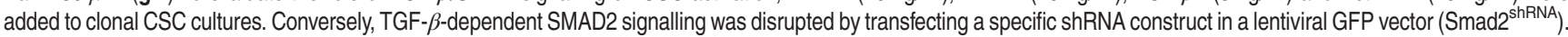
(g) Activin-A increases SMAD2 phosphorylation in treated versus untreated c-kit ${ }^{\text {Dos }}$ CSCs. The lentiviral construct carrying a specific shRNA for Smad2 efficiently downregulates SMAD2 in c-kit ${ }^{\text {pos }}$ CSCs. (h and i) Effect of TGF- $\beta$ family activation on c-kit ${ }^{\text {pos }}$ CSC proliferation (h) and clonogenicity (i). ${ }^{*} P<0.05$ versus all; ${ }^{\dagger} P<0.05$ versus $0 \%$ FBS serum starvation (for $48 \mathrm{~h}$ ). Data are mean \pm S.D., $n=6$. (j) TGF- $\beta$ family activation increases CM commitment of $\mathrm{c}$-kit ${ }^{\text {pos }} \mathrm{CSCs}$. ${ }^{*} P<0.05$ versus $\mathrm{CTRL}$; ${ }^{\dagger} P<0.05$ versus relative treatment. Data are mean \pm S.D., $n=6$. (k) Representative confocal image show CM (red, cTnl) committed cells in Activin-A-treated c-kit ${ }^{\text {os }}$ CSCs; DAPI stain nuclei in blue. Bar $=50 \mu \mathrm{m}$. (I) qRT-PCR analysis show the FC (over c-kit ${ }^{\text {pos }}$ CSCs in base differentiation medium) of Oct-4, c-kit, Gata-4, Nkx2.5 and cTnl mRNAs following 14 days in LIFdeprived differentiation medium in the absence (CTRL) or presence of Activin-A or Smad2 ${ }^{\text {shRNA }}+$ Activin-A. ${ }^{*} P<0.05$ versus $C T R L$. ${ }^{\dagger} P<0.05$ versus Activin-A. Data are mean \pm S.D., $n=3$ 
a

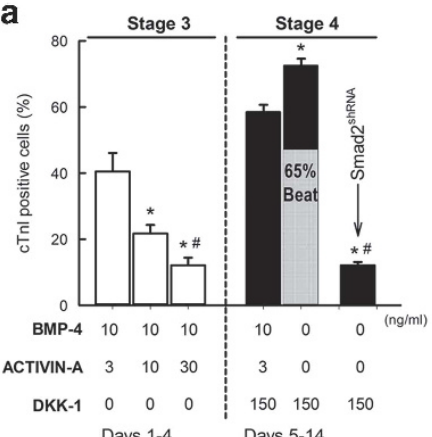

Days 1-4 b

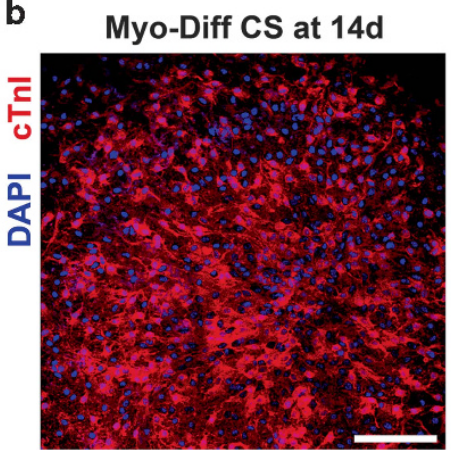

c

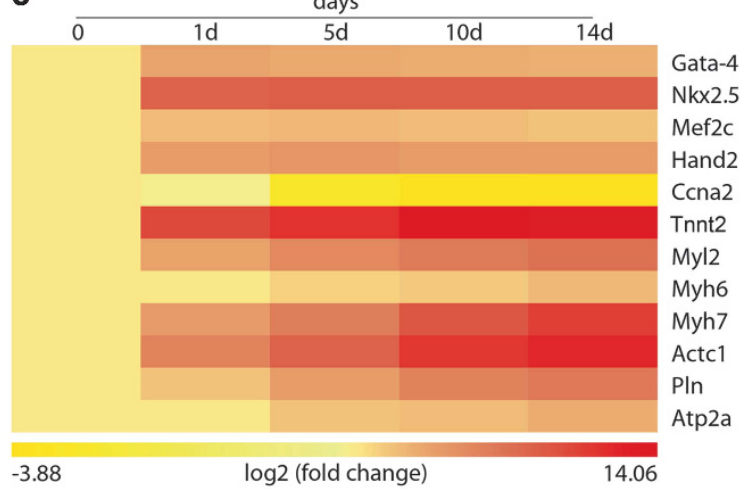

$-3.88$

$\log 2$ (fold change)

14.06

d
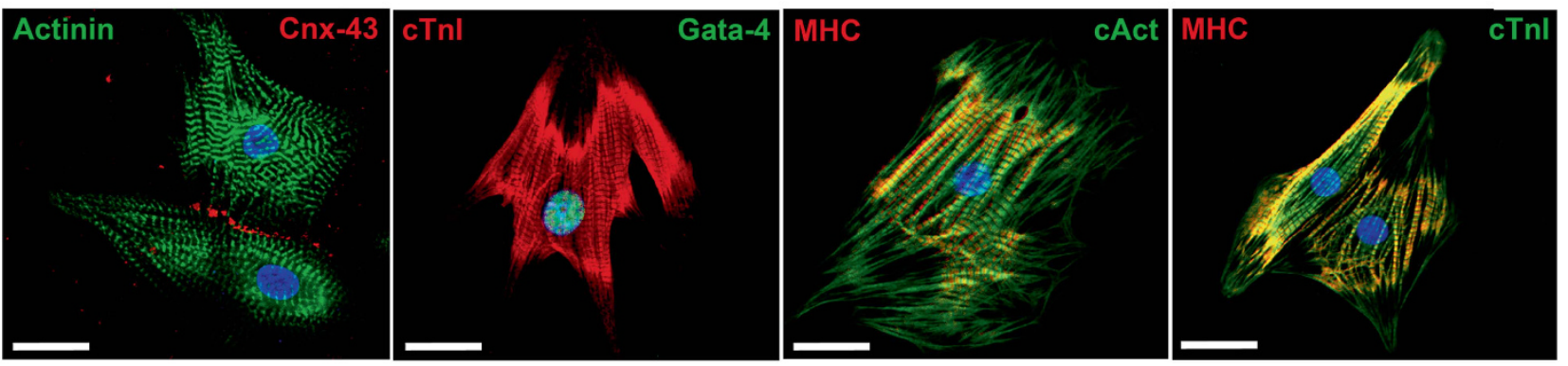

e

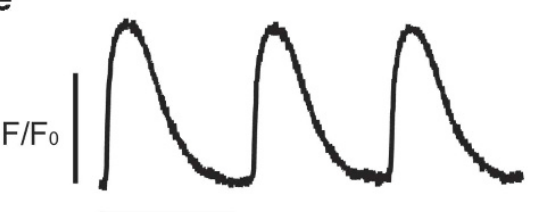

1s

h

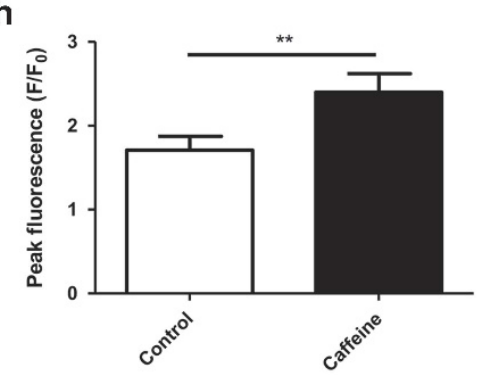

f

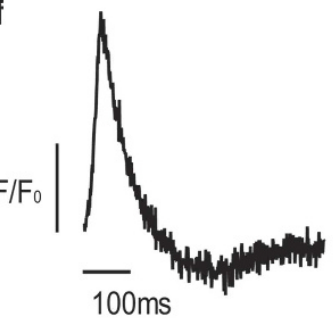

g

$40 \mu \mathrm{M}$ caffeine
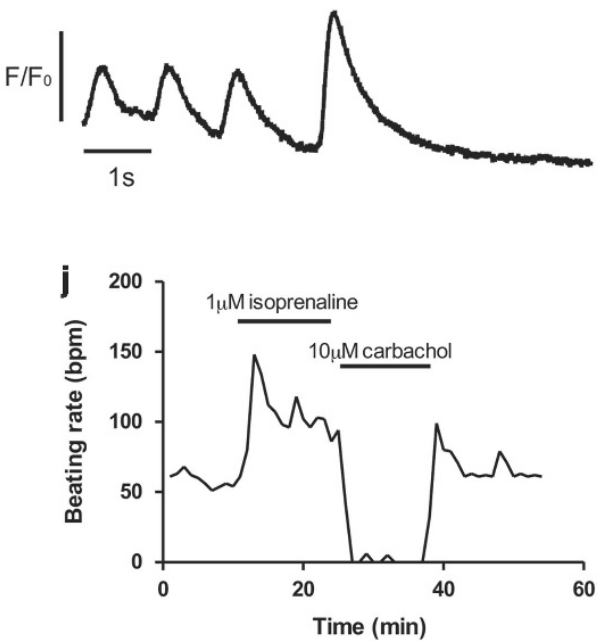

Figure 5 A stage-specific TGF- $\beta$-family/Wnt Inhibitor cocktail induces c-kit ${ }^{\text {pos }}$ CSC CSs to differentiate with high efficiency into spontaneously rhythmic beating functional CMs in vitro. (a) Frequency of cTnl-positive CM-committed cells and percentage of beating cells resulting from the indicated different TGF- $\beta$ Wnt cocktail strategies. ${ }^{*} P<0.05$ versus all. " versus stage 4. Data are mean \pm S.D., $n=6$. (b) Representative confocal image shows $c T n l$ (red) CM-committed cells at 14 days. DAPI stain nuclei in blue. $\mathrm{Bar}=50 \mu \mathrm{m}$. (c) qRT-PCR analysis heat map show sequential upregulation of cardiac transcription factors, followed by contractile genes with downregulation of cell cycle competence genes in differentiating c-kit ${ }^{\text {pos }}$ CSC CSs at different time points in the stage-specific TGF- $\beta$-family/Wnt inhibitor cocktail. Colour scale indicates change in Ct (threshold cycle) relative to the normalised GAPDH control. (d) CSC-derived contracting CMs express contractile proteins (Actinin, CTnl, MHC and cardiac Actin) with co-expression of cardiac transcription factor (Gata-4). The CSC-derived CMs exhibit well-defined sarcomeric structures (z lines and dots) as well as gap junction formation (Cnx43) between cells. DAPI stain nuclei in blue. Bar $=20 \mu \mathrm{m}$. (e) Representative traces of calcium transients stimulated at $1 \mathrm{~Hz}$, with change in fluo-4 fluorescence normalised to baseline (F/F0). (f) Representative trace of an action potential stimulated at $1 \mathrm{~Hz}$, with change in di-8-anepps fluorescence normalised to baseline (F/F0). (g) Representative trace of a caffeine-induced calcium transient, which is preceded by three normal calcium transients stimulated at $1 \mathrm{~Hz}$ with change in fluo-4 fluorescence normalised to baseline (F/F0). (h) Peak fluorescence (F/FO) compared between control calcium transients and caffeine-induced calcium transients indicating a functional sarcoplasmic reticulum $\left({ }^{\star \star} P<0.01\right.$, $n=6$ ). (i) Rate of calcium transient decay where $k T o t a l=k S E R C A+k N C X+k S l o w$ with proportion of calcium extruded by each mechanism represented below (** $P<0.01$, ${ }^{* * \star} P<0.005, n=6$ ). (j) Example trace of change in spontaneous beating rate with application of the non-selective $\beta$-adrenergic agonist, isoprenaline and the muscarinic acetylcholine receptor agonist, carbachol 
a

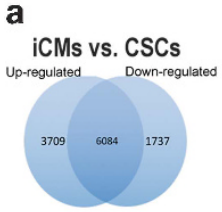

iCMs vs. aCMs

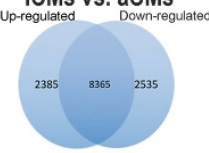

iCMs vs. neoCMs

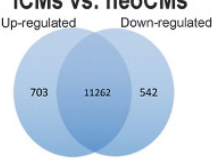

b

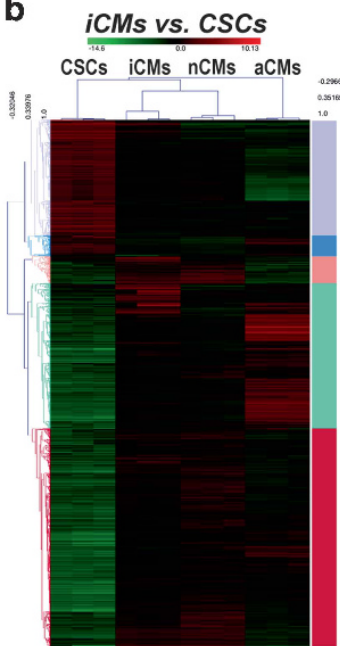

C

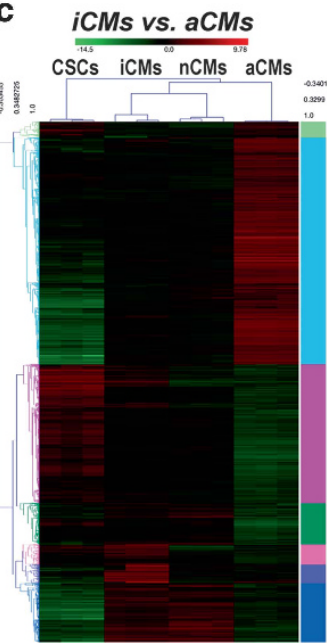

d

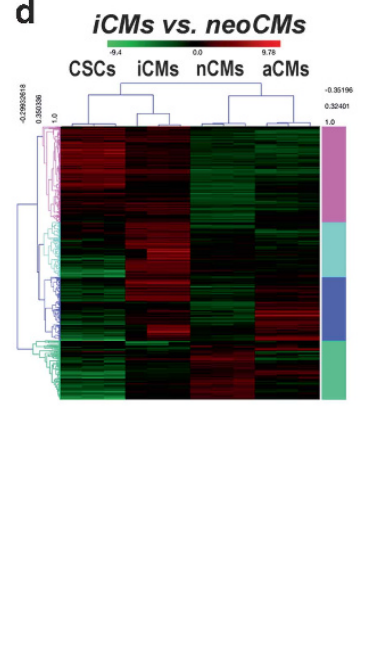

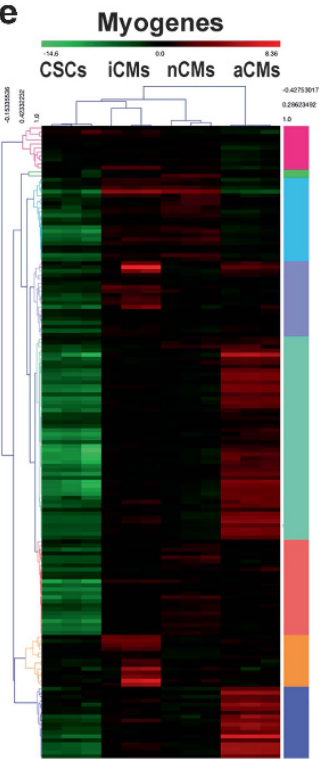

Figure 6 c-kit ${ }^{\text {pos }}$ CSC-derived CMs (iCMs) possess a genomic expression profile typical of aCMs. RNA-seq data were obtained using mRNA from cloned undifferentiated rat CSCs, beating colonies of iCMs at 21 days of the CM differentiation in vitro protocol, freshly isolated CMs from hearts of PN 1 to 2-day-old pups and from 12-week-old Wistar rats. (a) Venn diagram shows distribution of the number of common, downregulated and upregulated genes in the iCMs versus c-kittos CSCs, iCMs versus aCMs and iCMs versus neoCMs*. (b) Heat map of RNA-seq profile of the 1737 downregulated and 3709 upregulated genes in the iCMs versus c-kit ${ }^{\text {pos }}$ CSCs comparison and their GO clustering for specific gene function ${ }^{\dagger}$. (c) Heat map of RNA-seq profile of the 2385 upregulated and 2535 downregulated genes in the iCMs versus aCMs comparison and their GO clustering for specific gene function ${ }^{\dagger}$. (d) Heat map of RNA-seq profile of the 703 upregulated and 542 downregulated genes in the iCMs versus neoCMs comparison and their GO clustering for specific gene function ${ }^{\dagger}$. (e) Heat map of selected myogenic gene expression (like, Tnnc1, Tnnc2, Tnnt2, Tnnt3, Tnni3, Myh18b, Myh7, Myh6, Mybpc3, Myl2, Myl3 and Actn2) from RNA-seq analysis in the c-kitpos CSC versus iCM comparison (with accompanying relative expression of the same genes in neoCMs and aCMs) and their GO clustering for specific gene function ${ }^{\S}$. Note: specific FCs for each gene in the different comparisons and the gene IDs are reported in Supplementary Table S1a. ${ }^{\dagger}$ Note: each GO clustering for specific gene function is identified by the right vertical colour band. The GO cluster names and the identification of relative included gene names is reported in Supplementary Table S1b-d, respectively. ${ }^{\S}$ Note: selected myogenic gene names are grouped in different GO clustering for specific gene function that are identified by the right vertical colour band. The GO cluster names and the identification of relative included gene names is reported in Supplementary Table S1e

of the total cardiac c-kit ${ }^{\text {pos }}$ cells) have a robust cardiomyogenic potential and the capacity to functionally regenerate the infarcted myocardium through the SMAD2 signalling pathway. In contrast, the vast majority of $\mathrm{c}-\mathrm{kit}^{\mathrm{pos}}$ cardiac cells are not myogenic, and despite the vasculogenic potential, of most of them, do not repair the damaged myocardium at the functional level. Therefore, the vast majority of $\mathrm{c}-\mathrm{kit}^{\mathrm{pos}}$ cardiac cells are not and should not be considered CSCs.

\section{Discussion}

The principal findings of this study are as follows: (i) c-kit expression on its own cannot identify the small fraction of multipotent CSCs within the total c-kit ${ }^{\text {pos }}$ cardiac cell cohort; (ii) a consecutive negative/positive selection for CD45 and c-kit expression identifies a more restricted $(\sim 10 \%$ of the total $\mathrm{c}-\mathrm{kit}^{\mathrm{pos}}$ ) but still heterogeneous cardiac cell population, which contains practically all the resident CSCs. Among these CD $45^{\text {neg }}$ C-kit ${ }^{\text {pos }}$ cells there is a subpopulation representing $\leqslant 1-2 \%$ of the total cardiac $c-$ kit $^{\text {pos }}$ cell population that is clonogenic with consistent self-renewal capacity and multipotent cardiac differentiation potential; (iii) $\mathrm{CD} 45^{\text {neg }} \mathrm{C}-\mathrm{kit}^{\text {pos }}$ single-cell-derived clones exhibit a reproducibly similar genome-wide expression profile, which encompasses all the different CD markers, which have been used to date to identify CSCs; (iv) clonally derived CSCs show robust self-renewing and serial sub-cloning capacity, genome stability and multilineage cardiac cell differentiation potential; (v) a sequential stage-specific combination of canonical Wnt inhibitors and TGF- $\beta$ family agonists in vitro stimulates CSC differentiation into functional and spontaneously contracting cells with a cellular, electrophysiological and whole transcriptome phenotype characteristic of bona fide CMs; and (vi) progeny derived from a single CD $45^{\text {neg }}$ - - kit $^{\text {pos }}$ clonogenic CSC supports robust histological and functional myocardial regeneration when administered post AMI. These results are in stark contrast with the failure of the total cardiac c-kit ${ }^{\text {pos }}$ cell population to undergo significant myogenesis in vitro or in vivo and to support any meaningful cellular or functional regeneration post AMI.

These results should help to provide a plausible and experimentally grounded interpretation of the conflicting results recently reported about the nature, identifying markers, physiological and cardiomyogenic properties of the so-called

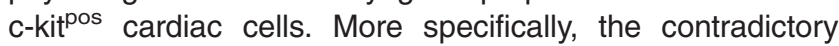
results about their role - or lack thereof - in the formation of new myocytes in adult mammalian myocardium homeostasis and repair can be easily explained by the very different nature

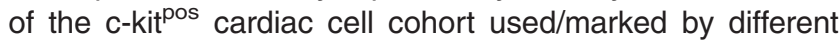
groups. ${ }^{1,9,15,17-24}$ Once the fact that true CSCs represent only $1-2 \%$ of the cardiac c-kit ${ }^{\text {pos }}$ cell population is acknowledged, the discordance between the results can easily be accounted 
a

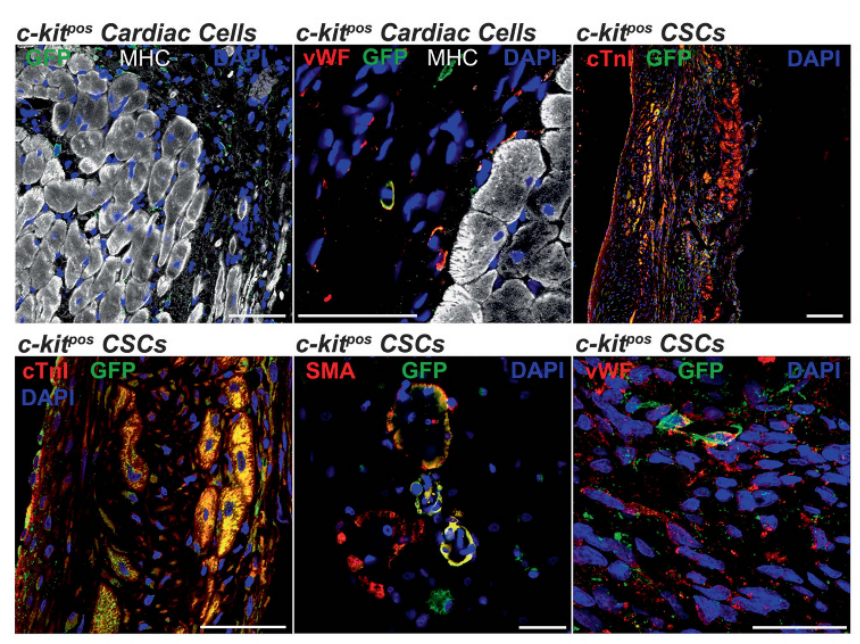

c

\section{Sham}

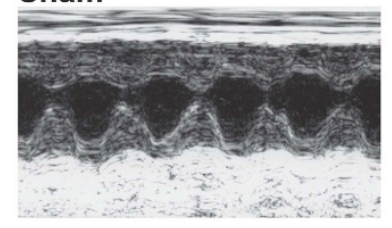

Ml+c-kit ${ }^{\text {pos }}$ Cardiac Cells

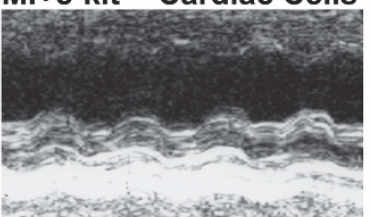

\section{MI+Saline}

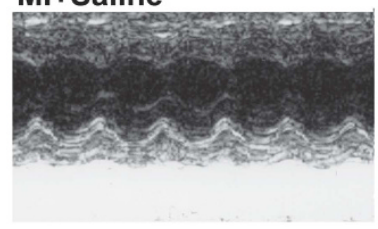

$\mathrm{Ml+c}-\mathrm{kit}^{\text {pos }} \mathrm{CSCs}$

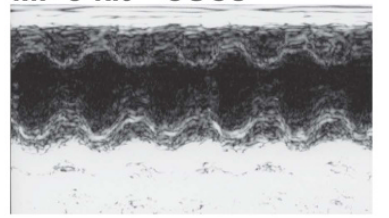

d 7.0
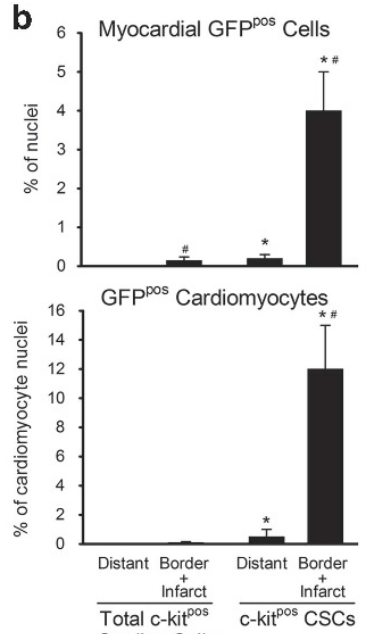
LVEDD

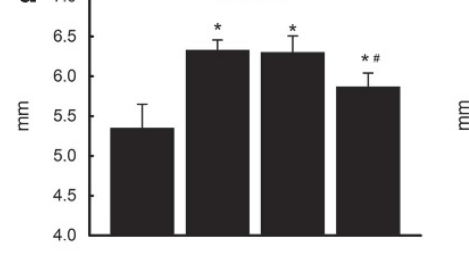

EF
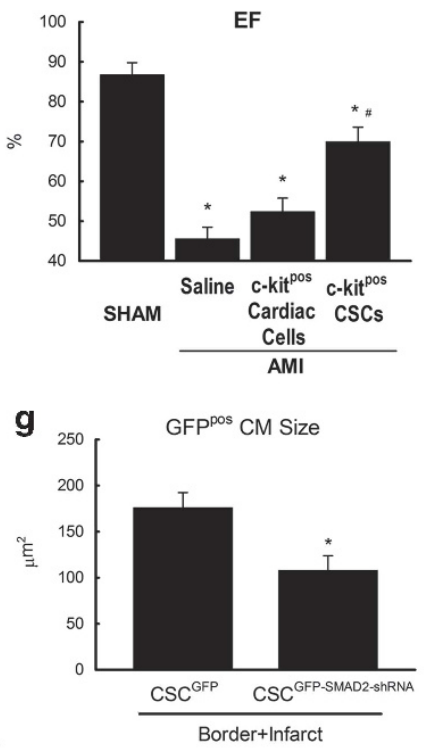

h

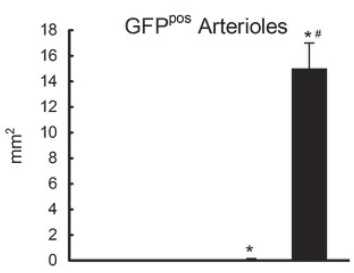

GFP $^{\text {pos }}$ Capillaries

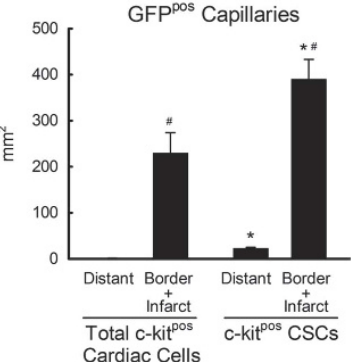

Cardiac Cells

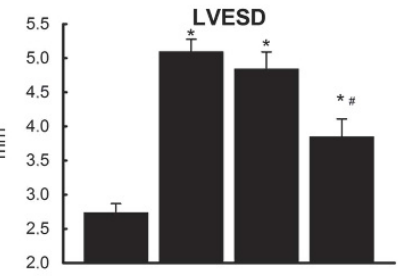

FS

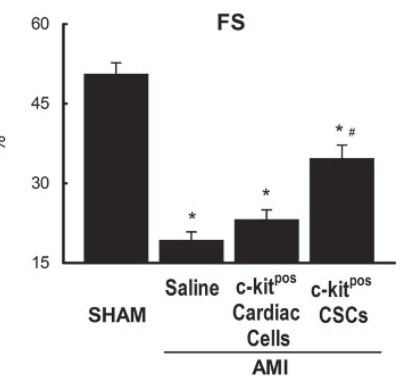

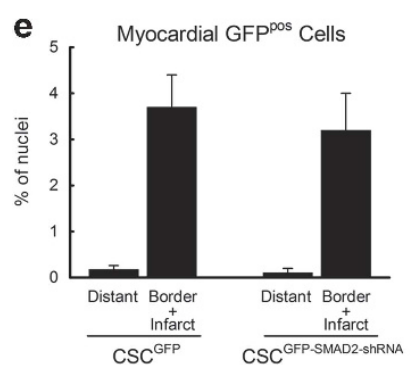
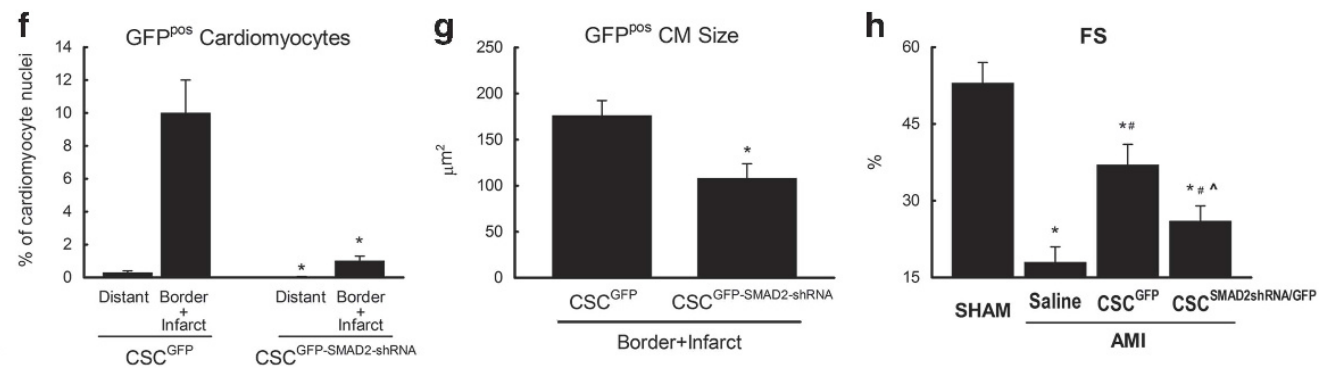

Figure $7 \quad c$-kit ${ }^{\text {pos }} \mathrm{CSC}$ not c-kit ${ }^{\text {pos }}$ cardiac cells are multipotent in vivo. (a) Representative confocal images show GFP-positive cell engraftment and differentiation 28 days after Ml in rats treated with GFP-transduced total c-kit ${ }^{\text {pos }}$ cardiac cells or c-kit ${ }^{\text {pos }} \mathrm{CSC}$. Most of the GFP ${ }^{\text {pos }} \mathrm{c}$-kit ${ }^{\text {pos }}$ cardiac cells acquired endothelial lineage specification (vWF, red, upper mid panel). On the contrary, GFPpos c-kittos CSCs differentiate into CMs (cTnl, red), arterioles (SMA, red) and capillaries (vWF, red). DAPI stain nuclei in blue. $\mathrm{Bar}=50 \mu \mathrm{m}$ except for upper right panel $=200 \mu \mathrm{m}$ and bottom right panel $=25 \mu \mathrm{m}$. (b) Bar graphs show cumulative data on total GFP cell engraftment, replenished GFPpos CMs, arterioles and capillaries in the different groups. ${ }^{*} P<0.05$ versus total $c$-kitpos cardiac cells; ${ }^{\#} P<0.05$ versus distant. Data are mean \pm S.D., $n=5$ per group. (c) Representative M-mode echocardiography images for Sham-operated animals and rats treated with saline, GFP ${ }^{\text {pos }}$ total c-kit ${ }^{\text {pos }}$ cardiac cells or GFP ${ }^{\text {pos }}$ c-kit ${ }^{\text {pos }}$ CSCs, 28 days after MI. (d) Bar graphs show cumulative echocardiographic data for LV end-diastolic diameter (LVEDD), LV end-systolic diameter (LVESD), ejection fraction (EF) and fractional shortening (FS) in the different groups. ${ }^{*} P<0.05$ versus Sham; and ${ }^{\#} P<0.05$ versus saline and total c-kit ${ }^{\text {pos }}$ cardiac cells. Data are mean \pm S.D., $n=5$ per group. (e-g) GFPpos

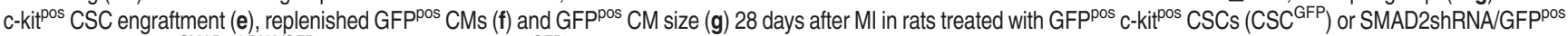
c-kitpos $\operatorname{CSCS}\left(\right.$ CSC $\left.^{\text {SMAD2ShRNAGFP }}\right){ }^{*} P<0.05$ versus CSC ${ }^{\text {GFP }}$. Data are mean \pm S.D., see Supplementary Table $S 2$ for $n$ values. (h) Echocardiographic data show FS 28 days

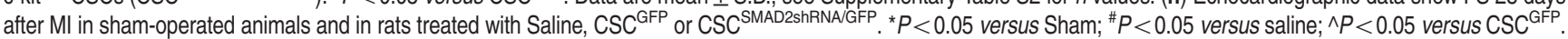
Data are mean \pm S.D., see Supplementary Table S2 for $n$ values 
for. The CSCs possess a robust myogenic and regenerative potential when injected into damaged myocardium (Figure 7; Supplementary Figures 9 and 10). In contrast, $>90 \%$ of cardiac c-kit ${ }^{\text {pos }}$ cells are endothelial cells and their precursors (Figure 1), and their transplantation produced significant neocapillarogenesis with no cardiomyogenesis, which did not improve ventricular function (Figure 7). This result explains why the genetic c-kit Cre/lox mouse lines mainly track endothelial cells ${ }^{22-24,47}$ and when total c-kit ${ }^{\text {pos }}$ cardiac cells are injected post AMI they show no cardiomyogenic potential. $^{20,46}$

The results described here indicate that expression of the stem cell receptor c-kit is an essential marker of the mammalian CSCs. Indeed, starting with highly heterogeneous cell populations, all single-cell clones that had the characteristics of bona fide CSCs were found to be c-kit ${ }^{\text {pos }}$ (Figure 1). In contrast, no clonogenic/self-renewing/mulitpotent cells were detected in the c-kit ${ }^{\text {neg }}$ cohort (Figure 1). Yet, on its own, c-kit expression in myocardial cells preferentially identifies mast and endothelial cell lineages. We have shown that combined use of a small set of positive/negative markers together with c-kit (Supplementary Figure S11) identifies the complete CSC cohort with exclusion of other lineage-committed c-kit ${ }^{\text {pos }}$ myocardial cell types. Therefore, we propose that the set of markers described here be considered a 'defining phenotype for the identification and isolation of mammalian adult endogenous CSCs', which needs to be taken into account in the design of any CSC cell-fate-tracking approach.

\section{Materials and Methods}

Experimental procedures were carried out under the British Home Office Animal (Scientific Procedures) Act 1986 or the Italian Ministry of Health Regulation for experimental animal use and approved by the corresponding Institutional Review Boards. Animals were housed under controlled conditions of $25^{\circ} \mathrm{C}, 50 \%$ relative humidity and $\mathrm{a} 12 \mathrm{~h}$ light (0600-1800 hours) and $12 \mathrm{~h}$ dark cycle, with water and food (containing $18.5 \%$ protein) available ad libitum.

Rat CM and CSC isolation. CMs and CSCs were isolated from adult male Wistar rat hearts by enzymatic dissociation. ${ }^{9,15}$ Hearts were excised, the aorta cannulated and hung on a retrograde perfusion system. Briefly, this procedure consists of three main steps: (1) a collagenase type II perfusion of the myocardium performed at $37^{\circ} \mathrm{C}$ with HEPES-MEM, gassed with $85 \% \mathrm{O}_{2}$ and $15 \% \mathrm{~N}_{2}$; (2) the heart is removed from the apparatus, cut into small pieces and the fragments shaken in re-suspension medium at $37^{\circ} \mathrm{C}$; and (3) $\mathrm{CMs}$ and small cardiac cells are separated by centrifugation. For isolation of $\mathrm{CD} 45^{\text {neg }} \mathrm{C}$-kit ${ }^{\text {pos }}$ cells, first the myocytedepleted small cardiac cells are incubated with an anti-rat CD45 antibody. After antibody binding, the $C D 45^{\text {pos }}$ cells are depleted from the preparation by MACS (Miltenyi, Cologne, Germany) using anti-Mouse IgG MicroBeads, leaving the CD45 ${ }^{\text {neg }}$ fraction. From the CD $45^{\text {neg }}$ fraction, the $c-k^{\text {pit }}{ }^{\text {pos }}\left(C D 45^{\text {neg }}\right)$ cardiac cells are enriched through incubation with a rabbit polyclonal antibody against c-kit, followed by indirect anti-rabbit lgG microbeads sorting (Miltenyi). ${ }^{9,15}$

All the specific antibodies are listed in Supplementary Table S3.

Mouse CSC isolation. The same procedure described above $e^{9,15}$ was used to isolate CSCs from adult mouse hearts but using MACS technology with direct CD45-negative and then c-kit-positive anti-mouse microbeads sorting (Miltenyi).

All the specific antibodies are listed in Supplementary Table S3.

Cell culture. Freshly isolated $\mathrm{CD} 45^{\text {neg }} \mathrm{c}-\mathrm{kit}^{\mathrm{pos}}$ cardiac cells were plated in gelatin-coated dishes in CSC growth medium ${ }^{9,15}$ consisting of Dulbecco's MEM/ Ham's F12 (DMEM/F12; Sigma, St. Louis, MO, USA) medium containing 10\% ESQFBS (Life Tech, ThermoScientific, Waltham, MA, USA), LIF (10 ng/ml; Miltenyi), FGF (10 ng/ml; Peprotech, Rocky Hill, NJ, USA), EGF (20 ng/ml; Peprotech), insulin-transferrin-selenite (Life Tech), EPO (2.5 U; Sigma, only for rat cells), 1\% pen-strep (Life Tech) and $0.1 \%$ gentamicin $(10 \mathrm{mg} / \mathrm{ml}$ liquid, Life Tech). Except where indicated (low oxygen), cells were maintained at $37^{\circ} \mathrm{C}$ in ambient $\mathrm{O}_{2}(21 \%)$ and $5 \% \mathrm{CO}_{2}$. Media were replenished every $48 \mathrm{~h}$ and cells were passaged at a $1: 4$ ratio.

Clonogenic and spherogenesis assay in vitro. To show clonogenicity, single-cell cloning was used through depositing single $\mathrm{CD} 45^{\text {neg }} c-\mathrm{kit}^{\text {pos }}$ cardiac cell or cloned CSC into wells of 96-well gelatin-coated Terasaki plates by serial dilution. Individual $C D 45^{\text {neg }} c-k_{i}{ }^{\text {pos }}$ cells were grown in mCSFM (see below) for 1-3 weeks when clones were identified and expanded. Mouse CSC clones were expanded on CELLstart (Life Technologies, Carlsbad, CA, USA) coated plates. The clonogenicity of the $C D 45^{\text {neg }} c-k i t^{\text {pos }}$ cells was determined by counting the number of wells in each 96-well plate, which contained clones and expressed as a percentage. Sub-cloning was performed at every tenth passage and maintenance of clonogenicity and stemness properties assessed. A total of 10 plates were analysed for each experiment.

For CS generation, $\mathrm{CD} 45^{\text {neg }} \mathrm{C}$-kit ${ }^{\text {pos }} \mathrm{CSC}$ s were placed in bacteriological dishes with CS generation medium (mCSFM) composed of 1:1 ratio of CSC growth medium and Neural Basal Media supplemented with B27 and N2 supplements (Life Tech). CSs were counted per plate at 14 days and the number expressed as a percentage relative to the number of plated CSCs. ${ }^{9,15}$

MethoCult assay in vitro. CFU formation from cloned versus freshly isolated CSCs was assessed by plating relative cells in $1.2 \mathrm{ml}$ of MethoCult medium (STEMCELL Technologies, Vancouver, Canada) (1\% methylcellulose in CSC growth medium). Colonies were counted at 14 days after plating.

BrdU incorporation in vitro and in vivo. To assess the proliferative activity of $\mathrm{CD}{ }^{\text {neg }}{ }^{\mathrm{C}}$-kit ${ }^{\text {pos }}$ cardiac cells, before harvest in culture, $\mathrm{BrdU}(50 \mathrm{mg} / \mathrm{kg})$ was intraperitoneally administered in vivo for 6 days in adult mice every $12 \mathrm{~h}$, before mouse killing, and then it was administered in the enzymatic solution $(10 \mu \mathrm{M})$ while digesting the hearts. After harvest in culture BrdU $10 \mu \mathrm{M}$ was administered in vitro every $12 \mathrm{~h}$ for 7 days on freshly isolated $\mathrm{CD} 45^{\mathrm{neg}} \mathrm{c}-\mathrm{kit}^{\mathrm{pos}}$ cardiac cells and $\mathrm{CD} 45^{\text {neg }} \mathrm{C}-\mathrm{kit}^{\text {pos }}$ cardiac cells at $\mathrm{P} 1$. Then cells were analysed by flow cytometry (PE Anti-BrdU Antibody, Biolegend, San Diego, CA, USA).

Differentiation potential, CS myogenic differentiation and spontaneous beating assay in vitro. Freshly isolated or cloned $\mathrm{CD}_{4} 5^{\text {neg }} \mathrm{C}-\mathrm{kit}^{\mathrm{pos}}$ CSCs were plated in LIF-deprived basic differentiation medium consisting of $\alpha$-MEM, dexamethasone $(1 \mu \mathrm{M})$, ascorbic acid $(50 \mu \mathrm{g} / \mathrm{ml}), \beta$-glycerophosphate (10 mM; all from Sigma) with 3\% FBS (Invitrogen, Carlsbad, CA, USA). For specific myocyte, vascular SMC and EC commitment, TGF- $\beta 1$ ( $5 \mathrm{ng} / \mathrm{ml}$, Peprotech), alltrans retinoic acid $\left(10^{-6} \mathrm{~mol} / \mathrm{l}\right.$, Sigma) and VEGF-A (10 $\mathrm{ng} / \mathrm{ml}$, PeproTech) were, respectively, added and complete differentiation media refreshed every $72 \mathrm{~h}$. Cell differentiation was evaluated at 14 days as previously described. ${ }^{9,15,48,49}$ Briefly, $\mathrm{CM}$, smooth muscle and endothelial differentiation was quantified by staining for cTnl, SMA and vWF, respectively. The nuclei were counterstained with 4, 6diamidino-2-phenylindole (DAPI). Cells were evaluated using fluorescence and confocal microscopy. In all, 10 random fields at $\times 20$ magnification were counted for each dish, and the percentage of cTnl-, SMA- or vWF-positive cells relative to the total number of cells was calculated. All analysis was performed by investigators who were blind to the group assignment.

To promote the Wnt/ $\beta$-catenin pathway, c-kit ${ }^{p o s} \mathrm{CSC}$ sere treated with soluble Wnt-3a (150 ng/ml, Peprotech), Wnt-3a-conditioned medium (from a Wnt-3asecreting cell line, ATCC, Manassas, VA, USA) or with BIO (2.5 $\mu \mathrm{M}$; Sigma). To disrupt Wnt/ $\beta$-catenin, cells were treated with Dkk-1 (150 ng/ml; R\&D System, MN, USA) or transfected with a lentiviral vector carrying a short hairpin RNA (shRNA) for rat $\beta$-catenin with a GFP reporter ( $\beta$-cat ${ }^{\text {shRNA }}$, Santa Cruz, TX, USA). To evaluate the role of TGF- $\beta /$ SMAD signalling, BMP-2 (10 ng/ml; Peprotech), BMP-4 $(10 \mathrm{ng} / \mathrm{ml}$; Peprotech), Activin-A (10 ng/ml; R\&D System) and TGF- $\beta 1$ ( $5 \mathrm{ng} / \mathrm{ml}$; Peprotech) were added in the medium. To distrupt TGF- $\beta 1$-dependent SMAD signalling, $c$-kit ${ }^{\text {pos }}$ CSC were transfected with lentiviral vector carrying a shRNA specific for rat Smad2 with a GFP reporter (Smad2 ${ }^{\text {shRNA }}$, Origene, Rockville, MD, USA). Lentiviral vectors for $\beta$-catenin and Smad2 shRNAs were infected at $100 \mathrm{MOI}$, and $48 \mathrm{~h}$ later, GFP expression was assessed by live imaging (FLoyd Cell Imaging Station, Life Technologies, Waltham, MA, USA) and cells were plated for differentiation or sphere formation as described above. CM differentiation was quantified by staining for $\mathrm{cTnl}$ as above described. 
For CS myogenic differentiation and spontaneous beating assay in vitro, cloned c-kitpos CSCs plated in flasks were treated with $100 \mathrm{nM}$ oxytocin for $72 \mathrm{~h}$ in leukaemia inhibitory factor-deprived CSC growth medium and then placed in bacteriological dishes with mCSFM for the generation of CSs for 4 days. Clonogenic c-kit ${ }^{\text {pos }}$ CSCderived CSs were transferred to laminin $(1 \mu \mathrm{g} / \mathrm{mll})$-coated dishes in base differentiation medium $(\alpha$-MEM), dexamethasone $(1 \mu \mathrm{M})$, ascorbic acid $(50 \mu \mathrm{g} / \mathrm{ml})$, $\beta$-glycerophosphate ( $10 \mathrm{mM}$; all from Sigma) with $2 \%$ FBS (Invitrogen). BMP-4 $(10 \mathrm{ng} / \mathrm{ml}$; Peprotech) and Activin-A (3, 10 or $30 \mathrm{ng} / \mathrm{ml})$ were added in the medium, changed after $48 \mathrm{~h}$ and removed at 4 days. At day 5, BMP-4 were removed and Dkk-1 $(150 \mathrm{ng} / \mathrm{ml}$; R\&D System) was added for the remainder of the culture period. At 14 days the number of beating CSs in each dish was calculated on the percentage of beating CSs relative to the total number of CSs/clusters in each dish. ${ }^{29}$ Then beating CSs were either trypsinised for RNA isolation or fixed with 4\% PFA and doublestained for actinin or CTnl and connexin 43 and detected by FITC- and TRICTconjugated secondary antibodies (2Abs), respectively. Nuclei were stained with DAPI.

All the specific antibodies are listed in Supplementary Table S3.

Flow cytometry. Cell analysis was performed on FACSCanto II (BD, San Jose, CA, USA) with FlowJo software (TREE STAR, Inc., OR, USA) to identify the percentage of cardiac small cells expressing different cell-surface markers of interest. Specific antibodies used are shown in Supplementary Table S3. Appropriate labelled isotype controls were used to define the specific gates. Freshly isolated $C D 45^{\text {pos }} \mathrm{c}-\mathrm{kit}^{\mathrm{pos}}$ cells were sorted on a BD FACSAria III (BD Biosciences, San Jose, CA, USA).

Immunocytochemistry. Mouse and rat c-kit ${ }^{\text {pos }} \mathrm{CSC}$ or $\mathrm{c}-\mathrm{kit}^{\text {pos }} \mathrm{CSC}$-derived CSs were cultured on glass chamber slides (Thermo Fischer Scientific) for 2 days, fixed with 4\% PFA for 20 min on ice and then stained. For intracellular staining, cells were permeabilised using $0.1 \%$ Triton $X-100$. Cells were incubated with the primary antibody overnight at $4{ }^{\circ} \mathrm{C}$, washed three times and then incubated secondary antibody (Jackson Immunoresearch, West Grove, PA, USA) for $1 \mathrm{~h}$ at $37^{\circ} \mathrm{C}$. Then cells were washed three times and nuclei were counterstained with DAPI (Sigma). Fluorescence was visualised and images acquired with confocal microscopy (TCS SP2, Leica, Wetzlar, Germany). Specific primary antibodies are listed in Supplementary Table S3. All secondary antibodies were purchased from Jackson Immunoresearch (1:100 dilution).

Cytospin. $\mathrm{CD} 45^{\text {neg }} \mathrm{C}-\mathrm{kit}^{\mathrm{pos}}$ cardiac cells were suspended in complete CSC growth medium. A volume of $200 \mu \mathrm{l}$ of a $0.3 \times 10^{6} \mathrm{cells} / \mathrm{ml}$ suspension were directly loaded in each cytofunnel and spin down at 800 r.p.m. for 3 min onto poly-lysinecoated slides using a Shandon Cytospin 4 Cytocentrifuge (Thermo Fisher Scientific, MA, USA). Slides were immediately fixed using a spray fixative (Shandon Cell-Fixx, Thermo Fisher Scientific) and then processed for immunostaining as above described. Fluorescence was visualised and images acquired with confocal microscopy (LEICA TCS SP2).

Quantitative RT-PCR. RNA was extracted from CMs and CSCs using TRIzol Reagent (Ambion, ThermoFisherScientific, Waltham, MA, USA) and quantitated using a Nanodrop 2000 Spectrophotometer (Thermo Fisher Scientific). Reverse transcription was performed with $0.5-1 \mu \mathrm{g}$ of RNA using the High Capacity cDNA Kit (Applied Biosystems, Foster City, CA, USA). qRT-PCR was performed using TaqMan Primer/Probe sets (Supplementary Table S4) using StepOne Plus real Time PCR System (Applied Biosystems). Data were processed by the $\Delta \mathrm{Ct}$ method using StepOne Software (Applied Biosystems) v2.3 and mRNA was normalised to the housekeeping gene, GAPDH. All reactions were carried out in triplicate.

Western blot analysis. Immunoblots and immunoprecipitations were carried out using protein lysates obtained from CSCs. Generally, aliquots equivalent of $\sim 50 \mu \mathrm{g}$ of protein were separated on gradient (6-15\%) SDS-polyacrylamide gels. After electrophoresis, proteins were transferred onto nitrocellulose filters, blocked with either $5 \%$ dry milk or $5 \%$ bovine serum albumin, and incubated with Abs against c-kit, $\beta$-catenin, active $\beta$-catenin, Smad2 and phospho-Smad2 at dilutions suggested by the manufacturers. Actin was used as a loading control. Proteins were detected by chemiluminescence using horseradish peroxidase-conjugated 2Abs and the Alliance UVITEC Cambridge system (Eppendorf, Hamburg, Germany).

\section{Electrophysiological functional assessment in vitro}

Optical mapping: Cytoplasmic $\mathrm{Ca} 2+$ concentration was monitored, loading the cells with Fluo-4-AM ( $4 \mu \mathrm{g} / \mathrm{ml}$, Invitrogen) for $20 \mathrm{~min}$. Cells were perfused at $37^{\circ} \mathrm{C}$ with normal Tyrode solution (140 mM NaCl, $4.5 \mathrm{mM} \mathrm{KCl}, 10 \mathrm{mM}$ glucose, $10 \mathrm{mM}$ HEPES, $1 \mathrm{mM} \mathrm{MgCl} 2,1.8 \mathrm{mM} \mathrm{CaCl} ; \mathrm{pH} 7.4)$ and field stimulated at $1 \mathrm{~Hz}(30 \mathrm{~V}$, $10 \mathrm{~ms}$ ). A $470 \mathrm{~nm}$ LED was used to excite the fluorophore, with emission passing through a $560 \pm 35 \mathrm{~nm}$ filter, before being recorded by a NeuroCMOS camera ( $0.25 \mathrm{kHz}$, Redshirt, Cairn Research, Kent, UK).

Membrane potential was monitored by loading di-8-ANEPPs ( $5 \mu \mathrm{M}$, Invitrogen) for $10 \mathrm{~min}$. The excitation-contraction uncoupler, blebbistatin ( $1 \mu \mathrm{M}$, Sigma), was used to minimise motion artefact. The conditions used above were used, with a $535 \mathrm{~nm}$ LED and $590 \mathrm{~nm}$ long-pass filter, recording at $1 \mathrm{kHz}$.

Calcium and action potential data were analysed using pClamp10 (Axon CNS Molecular Devices, Sunnyvale, CA, USA).

Caffeine application: Caffeine ( $40 \mu \mathrm{M}$; Sigma) was locally applied to cells using a glass micropipette, and calcium concentration was measured as above. Three stimulated transients were recorded before stimulation was turned off and caffeine applied. Caffeine potently locks open ryanodine receptor, and hence the caffeineinduced calcium transient is indicative of sarcoplasmic reticulum calcium content.

Rates of calcium transient decay were calculated based on an established method, ${ }^{1}$ by fitting a mono-exponential function to the decay in normal calcium transients and caffeine-induced calcium transients (as presence of caffeine removes contribution of SERCA) according to the equation: $k$ Total $=k S E R C A+k N C X+k S l o w$. Pharmacological manipulation of spontaneous beating rate: The spontaneous beating rate (b.p.m.) of clusters were measured using an lonOptix Myocyte Contractility System equipped with a Myocam-S camera scanning at $240 \mathrm{~Hz}$ (IonOptix Corp., Milton, MA, USA) fixed to a Nikon TE-200 inverted microscope. Baseline b.p.m. was measured for $10 \mathrm{~min}$ once stable, before application of the non-selective $\beta$-adrenergic agonist, isoprenaline ( $1 \mu \mathrm{M}$; Sigma) for $10 \mathrm{~min}$, followed by the muscarinic agonist, carbachol (10 $\mu \mathrm{M}$; Sigma) for $10 \mathrm{~min}$. Cells were then washed for reversal of the effect.

\section{RNA-seq}

RNA extraction: RNA was extracted from CMs and CSCs using TRIzol Reagent (Ambion). The extracted RNA integrity was measured with an Agilent 2100 Bioanalyzer (Agilent Technologies, Santa Clara, CA, USA), and a sample with an RNA integrity number $\geqslant 8$ was considered acceptable.

Library preparation: The libraries were generated using depleted RNA obtained from $1 \mu \mathrm{g}$ total RNA by TruSeq Sample Preparation RNA Kit (Illumina, Inc., San Diego, CA, USA) according to the manufacturer's protocol without further modifications. The first step involves the removal of ribosomal RNA (rRNA) using biotinylated, target-specific oligos combined with Ribo-Zero rRNA removal beads that depletes samples of both cytoplasmic and mitochondrial rRNA. Following purification, the RNA is fragmented into small pieces using divalent cations under elevated temperature. The cleaved RNA fragments are copied into first strand cDNA using reverse transcriptase and random primers, followed by second strand cDNA synthesis using DNA Polymerase I and RNase $\mathrm{H}$. These cDNA fragments then have the addition of a single ' $A$ ' base and subsequent ligation of the adapter (multiple indexing adapters were ligate to the ends of the ds $C D N A$ ). The products are purified and enriched with PCR to create the final CDNA library.

Sequencing: All libraries were sequenced on the Illumina HiSeq 1000 generating $100 \mathrm{bp}$ paired-end reads. The libraries were divided into two groups depending on how they were prepared.

Bioinformatics analysis: mapping reads to the reference genome: To perform RNA-seq data analysis, we used Strand NGS tools (http://www.strand-ngs. com). We set transcriptome and genome with novel splices as alignment and we use Ensembl (http://www.ensembl.org/index.html) as transcript model. Raw data sequences (that is, reads) have been pre-processed and then been related to rattus norvegicus genome (rno5). Parameters have been set as follows: (i) minimum percentage identity $=90 \%$; (ii) maximum percentage gaps $=5 \%$; (iii) maximum number of novel splices $=1$; and (iv) minimum match length $=25$. Reads with $<5$ valid matches have been filtered out, finally obtaining expression values for reads (quantification phase). To detect novel genes and exons we set the parameters, in term of percentile, as follows: minimum exon length equals to 10.0; minimum intron length equals to 10.0; maximum intron length equals to 90.0 ; minimum gene length equals to 10.0; minimum exon RPKM equals to 50.0, where RPKM, stands for reads per kilo base per million reads, used to represent read counts over a region of interest.

Differential expressions were performed using DESeq algorithm, available in StrandNGS (Strand Life Sciences, Bangalore, KA, India). We performed FC analysis on filtered expression values using normalised signal values that are in log-scale. We considered a FC cut off equals to 1.5 to identify up- and downregulated genes. For the experiment on the four rat CSC clones, we filtered on expression values getting 
27549 of interest genes as results. Similarly, for the comparison of CSCs versus iCMs versus aCMs data we obtained 27808 entities. GO (http://www.geneontology. org/) enrichment analysis has been performed to relate genes to biological processes, finding significantly enriched GO terms to be compared with the analysed data set. Heat maps have been created using MeV software (http://www.tm4.org/mev. html), and a hierarchical clustering has been performed using Pearson's correlation as distance metric and average linkage clustering as linkage method identifying several cluster enriched with DAVID for the functional analysis. DAVID has been used to select biological and molecular processes, and pathways of interests for the analysed data set. Statistic values are used to select the more interesting set of genes in terms of biological processes to annotate and guide clustering analysis.

Finally, ingenuity pathway analysis (http://www.ingenuity.com) has been performed to identify the main entities related to biological function and diseases. The most expressed genes have been loading into IPA and functions analysis has been performed using 0.05 as threshold value. The RNAseq data reported in this paper are publically available through the GEO accession number GSE95420.

Myocardial infarction. In the in vivo study comparing the cardiac

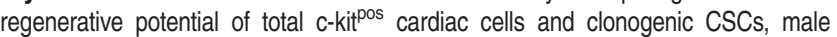
Wistar rats $(280 \pm 10 \mathrm{~g})$ were subjected to Ml through permanent ligation of left descendant anterior coronary artery as previously described. ${ }^{1,9}$ Thirty minutes later, $2 \times 10^{5} \mathrm{c}^{-k_{i} t^{\text {pos }}}$ GFP-tagged total c-kit ${ }^{\text {pos }}$ cardiac cells, $2 \times 10^{5} \mathrm{c}^{- \text {kit }^{\text {pos }}}$ GFP-tagged CSCs or just saline were transplanted in the border infarct zone. ${ }^{1,9}$ Additional rats served as sham-operated controls (Sham). Animals were then killed 28 days later. For the number of animals for each group see Supplementary Table 2. For the Ml animals, animals were excluded at first echocardiographic assessment if the EF was $\geqslant 70 \%$, indicating limited or no $\mathrm{Ml}$ had been induced.

Finally, additional rats $(n=3)$ with LAD ligation treated with GFP-tagged CSCs were killed 28 days after $\mathrm{Ml}$ and $\mathrm{CMs}$ isolated as described above. Area profile of rod-shaped CSC-derived $\mathrm{GFP}^{+} \mathrm{CMs}$ was evaluated as compared to GFP-negative spared pre-existing host $\mathrm{CMs}$ from same isolated CM preparations. To this aim, fluorescent microscopic examination was used to capture images of GFPpos and GFPneg rod-shaped CMs. CM length and width (from which profile area was calculated) were measured using ImageJ software (National Institutes of Health, Bethesda, MD, USA).

Echocardiography. Echocardiograms were obtained using a Vivid-Q ultrasound system (GE Healthcare, IL, USA) as previously reported by our laboratory. ${ }^{9}$ Animals were anaesthetised with the minimum amount of inhaled isoflurane needed to prevent movement and placed in the supine position. Hair was removed from the chest and LV images were obtained using a $12 \mathrm{~L}-\mathrm{RS}$ transducer (5.0-13.0 MHz, GE Healthcare) placed parasternally. Parasternal long- and shortaxis views were obtained with both $\mathrm{M}$-mode and two-dimensional echocardiography. LV dimensions (LV end-diastolic diameter and LV end-systolic diameter) were measured perpendicular to the long axis of the ventricle at the mid-chordal level on three consecutive cycles and averaged by two independent observers (IA and EC) in a blinded manner. Fractional shortening and LV ejection fraction were accordingly calculated. The numbers of animals for these determinations were as described above.

Tissue harvesting, histology and immunohistochemistry on LV cross sections. After completion of the echocardiographic measurements, the abdominal aorta was cannulated and the heart arrested in diastole using cadmium chloride (CdCl2). The isolated hearts were perfused with $10 \%$ buffered formalin and cut into right and left ventricles, and right and left atria. ${ }^{9}$ After being weighed, the LV was sectioned into three parts, that is, apical, mid and basal regions, embedded in paraffin and $5 \mu \mathrm{m}$ cross sections were prepared on a microtome (Leica, Wetzlar, Germany).

Apoptosis was detected on $5 \mu \mathrm{m} \mathrm{LV}$ sections using the terminal deoxynucleotidyltransferase (TdT) assay. ${ }^{9,48}$ Apoptotic (TdT-positive) myocytes were identified and quantified ( 3000 myocytes were counted per heart and the apoptotic fraction was expressed as a per cent of total myocyte nuclei) using light, fluorescent (Nikon E1000M) and confocal microscopy (Zeiss LSM 510, Oberkochen, Germany).

Myocyte diameters was measured across the nucleus on transverse $\mathrm{H \& E}$ sections of border infarct zone of the LV ( $\sim 500$ myocytes/animal were sampled). ${ }^{48,49}$ The numbers of animals for these determinations were as described above.

Antigen retrieval was achieved using Target Retrieval Solution, Citrate pH 6 (DAKO, Santa Clara, CA, USA). Myocyte cytoplasm was detected using an antibody against $\alpha$-sarcomeric actin (1:50 dilution; clone 5C5, Sigma), Myosin heavy chain (1:50 dilution, clone NOQ7.5.4D, Sigma) or cardiac Troponin I (1:50 dilution; rabbit polyclonal, Santa Cruz) for $2 \mathrm{~h}$ at $37^{\circ} \mathrm{C}$ and this was detected with anti-mouse lgM or IgG anti-rabbit IgG Texas Red (1:100 dilution; Jackson Immunoresearch). GFP ${ }^{\text {pos }}$ cells were detected using a goat polyclonal or rabbit polyclonal antibody against GFP (1:50 dilution; Rockland Immunochemicals (goat); (Pottsdown, PA, USA) Abcam (rabbit)) for $1 \mathrm{~h}$ at $37^{\circ} \mathrm{C}$ and this was detected with an anti-goat or anti-rabbit lgG FITC (1:100 dilution; Jackson Immunoresearch). GFP-positive CMs, SMCs, fibroblasts and ECs (capillaries) were identified on LV cross sections by double staining for GFP and cTnl, or SMA or vWF (1:100 dilution). Secondary Ab incubations were carried out at $37^{\circ} \mathrm{C}$ for $1 \mathrm{~h}$. The nuclei were counterstained with the DNAbinding dye, DAPI (Sigma) at $1 \mu \mathrm{g} / \mathrm{ml}$. Sections were mounted in Vectashield and analysed and scanned using confocal microscopy (Zeiss LSM 710 or Leica TCS SP5).

For the in vivo regeneration $\mathrm{Ml}$ assay, total GFP ${ }^{\text {pos }}$ cells, GFP ${ }^{\text {pos }} / \mathrm{CTn}^{\text {pos }}$, myocytes, GFP ${ }^{\text {pos }} / \mathrm{SMA}^{\text {pos }}$ arterioles and GFP ${ }^{\mathrm{pos}} / \mathrm{NWF}^{\mathrm{pos}}$ capillaries were counted in the border/infarct and distal areas by counting at $\times 63$ magnification a total of 20 fields in each area. The counts were pooled for border and infarct, making Border+Infarct. The number of GFPpos engrafted cells was expressed as a per cent fraction of the total number of nuclei. The number of GFP ${ }^{\text {pos }}$-cell-derived CMs was expressed as a per cent fraction of the total myocyte nuclei. Finally, the number of GFP ${ }^{\text {pos }}$-cellderived arterioles and capillaries was computed to $\mathrm{mm}^{2}$.

Statistical analysis. Statistical analysis was performed with GraphPad Prism version 6.00 for Macintosh (GraphPad Software, La Jolla, CA, USA). Quantitative data are reported as mean \pm S.E. and binary data by counts. Significance between two groups was determined by Student's $t$-test or paired $t$-test as appropriate. For comparison between multiple groups, ANOVA was used. A $P$-value $<0.05$ was considered significant. Bonferroni post hoc method was used to locate the differences. In these cases, the type 1 error $(\alpha=0.05)$ was corrected by the number of statistical comparisons performed.

For the in vitro cell and molecular biology experiments with an $n=4$ sample size, giving the low number of the sample, the Kruskal-Wallis test (for multiple-group comparison) and the Mann-Whitney U-test (for comparison between two groups) were performed.

Biological replicates have been defined as parallel measurements of biologically distinct samples. Technical replicates are repeated measurements of the same analysed sample that represent independent measures of the random noise associated with protocols or equipment. All the $N$ values in the manuscript are biological replicates unless specifically stated.

The $N$ per group and exact $P$-values for each experiment are reported in each figure or table legends.

Power calculations were performed to estimate animal numbers for the Ml and cell injection experiment. On the basis of preliminary results from CSCs injected into $\mathrm{MI}$ rat hearts where EF was measured, with $P<0.05$; a statistical power of 0.8 ; a difference of $8 \%$ between 1 day after Ml and 28 days after Ml+CSCs; and a S.D. of 4 , the estimated sample size generated from a Minitab software (State College, PA, USA) effect size curve is 6 . To allow for an expected mortality of $\sim 25 \%$ following MI, we used at least 10 animals/group.

\section{Conflict of Interest}

The authors declare no conflict of interest.

Acknowledgements. We assume responsibility for the accuracy and completeness of the reported data and analyses and for having conducted the study according to the approved protocol. We thank Professor Sian E Harding and her support through the BHF Cardiovascular Regenerative Medicine Centre RM/13/1/ 30157. This work was supported by grants from Italian Ministry of Education, University and Research, FIRB-Futuro-in-Ricerca Programme (RBFR1213KA), Italian Ministry of Health (GR-2010-2318945), CARE-MI FP7 (Health-F5-2010-242038) and Endostem FP7 (Health-F5-2010-241440) large-scale collaborative projects and BHF Cardiovascular Regenerative Medicine Centre.

1. Beltrami AP, Barlucchi L, Torella D, Baker M, Limana F, Chimenti S et al. Adult cardiac stem cells are multipotent and support myocardial regeneration. Cell 2003; 114: 763-776.

2. Martin CM, Meeson AP, Robertson SM, Hawke TJ, Richardson JA, Bates S et al. Persisten expression of the ATP-binding cassette transporter, Abcg2, identifies cardiac SP cells in the developing and adult heart. Dev Biol 2004; 265: 262-275. 
3. Matsuura K, Nagai T, Nishigaki N, Oyama T, Nishi J, Wada H et al. Adult cardiac Sca-1positive cells differentiate into beating cardiomyocytes. J Biol Chem 2004; 279: 11384-11391.

4. Chong JJ, Chandrakanthan V, Xaymardan M, Asli NS, Li J, Ahmed I et al. Adult cardiacresident MSC-like stem cells with a proepicardial origin. Cell Stem Cell 2011; 9: 527-540.

5. Oyama T, Nagai T, Wada H, Naito AT, Matsuura K, Iwanaga K et al. Cardiac side population cells have a potential to migrate and differentiate into cardiomyocytes in vitro and in vivo. J Cell Biol 2007; 176: 329-341.

6. Noseda M, Harada M, McSweeney S, Leja T, Belian E, Stuckey DJ et al. PDGFR $\alpha$ demarcates the cardiogenic clonogenic Sca1(+) stem/progenitor cell in adult murine myocardium. Nat Commun 2015; 6: 6930.

7. Messina E, De Angelis L, Frati G, Morrone S, Chimenti S, Fiordaliso F et al. Isolation and expansion of adult cardiac stem cells from human and murine heart. Circ Res 2004; 9: 911-921.

8. Smith RR, Barile L, Cho HC, Leppo MK, Hare JM, Messina E et al. Regenerative potential of cardiosphere-derived cells expanded from percutaneous endomyocardial biopsy specimens. Circulation 2007; 115: 896-908.

9. Ellison GM, Vicinanza C, Smith AJ, Aquila I, Leone A, Waring CD et al. Adult c-kit(pos) cardiac stem cells are necessary and sufficient for functional cardiac regeneration and repair. Cell 2013; 154: 827-842.

10. Nadal-Ginard B, Ellison GM, Torella D. The cardiac stem cell compartment is indispensable for myocardial cell homeostasis, repair and regeneration in the adult. Stem Cell Res 2014; 13: $615-630$.

11. Dey D, Han L, Bauer M, Sanada F, Oikonomopoulos A, Hosoda T et al. Dissecting the molecular relationship among various cardiogenic progenitor cells. Circ Res 2013; 112: 1253-1262.

12. Anversa $P$, Sussman $M A$, Bolli R. Molecular genetic advances in cardiovascular medicine: focus on the myocyte. Circulation 2004; 109: 2832-2838.

13. Dawn B, Stein AB, Urbanek K, Rota M, Whang B, Rastaldo $R$ et al. Cardiac stem cells delivered intravascularly traverse the vessel barrier, regenerate infarcted myocardium, and improve cardiac function. Proc Natl Acad Sci USA 2005; 102: 3766-3771.

14. Limana F, Germani A, Zacheo A, Kajstura J, Di Carlo A, Borsellino G et al. Exogenous high-mobility group box 1 protein induces myocardial regeneration after infarction via enhanced cardiac C-kit+ cell proliferation and differentiation. Circ Res 2005; 97 e73-e83.

15. Smith AJ, Lewis FC, Aquila I, Waring CD, Nocera A, Agosti $V$ et al. Isolation and characterization of resident endogenous c-kit-positive cardiac stem cells (eCSCs) from the adult mouse and rat heart. Nat Protoc 2014; 9: 1662-1681.

16. Sperr WR, Bankl HC, Mundigler G, Klappacher G, Grossschmidt K, Agis $\mathrm{H}$ et al. The human cardiac mast cell: localization, isolation, phenotype, and functional characterization. Blood 1994; 84: 3876-3884.

17. Pouly J, Bruneval P, Mandet C, Proksch S, Peyrard S, Amrein $C$ et al. Cardiac stem cells in the real world. J Thorac Cardiovasc Surg 2008; 135: 673-678.

18. Sandstedt J, Jonsson M, Lindahl A, Jeppsson A, Asp J. C-kit+ CD45- cells found in the adult human heart represent a population of endothelial progenitor cells. Basic Res Cardiol 2010; 105: 545-556.

19. van Berlo JH, Molkentin JD. An emerging consensus on cardiac regeneration. Nat Med 2014; 20: 1386-1393.

20. Zaruba MM, Soonpaa M, Reuter S, Field LJ. Cardiomyogenic potential of C-kit(+)-expressing cells derived from neonatal and adult mouse hearts. Circulation 2010; 121: 1992-2000.

21. Jesty SA, Steffey MA, Lee FK, Breitbach M, Hesse M, Reining S et al. c-kitt precursors support postinfarction myogenesis in the neonatal, but not adult, heart. Proc Natl Acad Sci USA 2012; 109: 13380-13385.

22. van Berlo JH, Kanisicak O, Maillet M, Vagnozzi RJ, Karch J, Lin SC et al. c-kit+ cells minimally contribute cardiomyocytes to the heart. Nature 2014; 509: 337-341.

23. Sultana N, Zhang L, Yan J, Chen J, Cai W, Razzaque S et al. Resident c-kit(+) cells in the heart are not cardiac stem cells. Nat Commun 2015; 6: 8701.

24. Liu $Q$, Yang $R$, Huang $X$, Zhang $H$, He L, Zhang $L$ et al. Genetic lineage tracing identifies in situ Kit expressing cardiomyocytes. Cell Res 2016; 26: 119-130.

25. van Berlo JH, Molkentin JD. Most of the dust has settled: cKit+ progenitor cells are an irrelevant source of cardiac myocytes in vivo. Circ Res 2016; 118: 17-19.

26. Keith MC, Bolli R. "String theory" of c-kit(pos) cardiac cells: a new paradigm regarding the nature of these cells that may reconcile apparently discrepant results. Circ Res 2015; 116: 1216-1230.

27. Bianco P, Cao X, Frenette PS, Mao JJ, Robey PG, Simmons PJ et al. The meaning, the sense and the significance: translating the science of mesenchymal stem cells into medicine. Nat Med 2013; 19: 35-42.

28. He S, Nakada D, Morrison SJ. Mechanism of stem cell self-renewal. Annu Rev Cell Dev Biol 2009; 25: 377-406

29. Birket MJ, Mummery CL. Pluripotent stem cell derived cardiovascular progenitors-a developmental perspective. Dev Biol 2015; 400: 169-179.
30. Buckingham M, Meilhac S, Zaffran S. Building the mammalian heart from two sources of myocardial cells. Nat Rev Genet 2005; 6: 826-835.

31. Wilson A, Laurenti E, Oser G, van der Wath RC, Blanco-Bose W, Jaworski M et al. Hematopoietic stem cells reversibly switch from dormancy to self-renewal during homeostasis and repair. Cell 2008; 135: 1118-1129.

32. Mercola M, Ruiz-Lozano P, Schneider MD. Cardiac muscle regeneration: lessons from development. Genes Dev 2011; 25: 299-309.

33. Noseda M, Peterkin T, Simões FC, Patient R, Schneider MD. Cardiopoietic factors: extracellular signals for cardiac lineage commitment. Circ Res 2011; 108: 129-152.

34. Goumans MJ, de Boer TP, Smits AM, van Laake LW, van Vliet P, Metz CH et al. TGF-beta1 induces efficient differentiation of human cardiomyocyte progenitor cells into functional cardiomyocytes in vitro. Stem Cell Res 2007; 1: 138-149.

35. Cohen ED, Wang Z, Lepore JJ, Lu MM, Taketo MM, Epstein DJ et al. Wnt/beta-catenin signaling promotes expansion of Isl-1-positive cardiac progenitor cells through regulation of FGF signaling. J Clin Invest 2007; 117: 1794-1804.

36. Qyang Y, Martin-Puig S, Chiravuri M, Chen S, Xu H, Bu L et al. The renewal and differentiation of Is $1+$ + cardiovascular progenitors are controlled by a Wnt/beta-catenin pathway. Cell Stem Cell 2007; 1: 165-179.

37. Klaus A, Müller M, Schulz H, Saga Y, Martin JF, Birchmeier W. Wnt/ $\beta$-catenin and Bmp signals control distinct sets of transcription factors in cardiac progenitor cells. Proc Natl Acad Sci USA 2012; 109: 10921-10926.

38. Kattman SJ, Witty AD, Gagliardi M, Dubois NC, Niapour M, Hotta A et al. Stage-specific optimization of Activin-A/nodal and BMP signaling promotes cardiac differentiation of mouse and human pluripotent stem cell lines. Cell Stem Cell 2011; 8: 228-240.

39. Bers DM. Cardiac excitation-contraction coupling. Nature 2002; 415: 198-205.

40. Maier LS, Zhang T, Chen L, DeSantiago J, Brown JH, Bers DM. Transgenic CaMKIIIc overexpression uniquely alters cardiac myocyte $\mathrm{Ca} 2+$ handling: reduced $\mathrm{SR} \mathrm{Ca} 2+$ load and activated SR Ca2+ release. Circ Res 2003; 92: 904-911.

41. Kane C, Couch L, Terracciano CMN. Excitation-contraction coupling of human induced pluripotent stem cell-derived cardiomyocytes. Front Cell Dev Biol 2015; 3: 1-8.

42. Bassani JW, Qi M, Samarel AM, Bers DM. Contractile arrest increases sarcoplasmic reticulum calcium uptake and SERCA2 gene expression in cultured neonatal rat heart cells. Circ Res 1994; 74: 991-997.

43. Nadal-Ginard B, Mahdavi V. Molecular basis of cardiac performance. Plasticity of the myocardium generated through protein isoform switches. J Clin Invest 1989; 84: 1693-1700.

44. Später D, Hansson EM, Zangi L, Chien KR. How to make a cardiomyocyte. Development 2014; 141: 4418-4431.

45. O'Meara CC, Wamstad JA, Gladstone RA, Fomovsky GM, Butty VL et al. Transcriptional reversion of cardiac myocyte fate during mammalian cardiac regeneration. Circ Res. 2015;116: 804-15.

46. Tang XL, Li Q, Rokosh G, Sanganalmath S, Chen N, Ou Q et al. Long-Term Outcome of Administration of c-kitPOS Cardiac Progenitor Cells After Acute Myocardial Infarction: Transplanted Cells Do Not Become Cardiomyocytes, but Structural and Functional Improvement and Proliferation of Endogenous Cells Persist for At Least One Year. Circ Res. 2016 Apr 1;118(7): 1091-105.

47. Nadal-Ginard B, Ellison GM, Torella D. Absence of evidence is not evidence of absence: pitfalls of cre knock-ins in the c-Kit locus. Circ Res. 2014:115: 415-418.

48. Ellison GM, Torella D, Dellegrottaglie S, Perez-Martinez C, Perez de Prado A, Vicinanza C et al. Endogenous cardiac stem cell activation by insulin-like growth factor-1/hepatocyte growth factor intracoronary injection fosters survival and regeneration of the infarcted pig heart. J Am Coll Cardiol. 2011;58: 977-986.

49. Waring CD, Vicinanza C, Papalamprou A, Smith AJ, Purushothaman S, Goldspink DF et al. The adult heart responds to increased workload with physiologic hypertrophy, cardiac stem cell activation, and new myocyte formation. Eur Heart J. 2014;35: 2722-2731.

(c) (1) () $\Theta$ This work is licensed under a Creative Commons Attribution-NonCommercial-NoDerivs 4.0 International License. The images or other third party material in this article are included in the article's Creative Commons license, unless indicated otherwise in the credit line; if the material is not included under the Creative Commons license, users will need to obtain permission from the license holder to reproduce the material. To view a copy of this license, visit http://creativecommons.org/licenses/by-nc-nd/4.0/
(C) The Author(s) 2017 